JGR Oceans

\author{
RESEARCH ARTICLE \\ 10.1029/2019JC016003 \\ Key Points: \\ - Coastal Benguela Niño events tend \\ to precede equatorial Atlantic Niños \\ by $\sim 1$ month, which is surprising \\ given their remote forcing \\ mechanism \\ - Interannual coastal wind-stress \\ variability increases the remotely \\ forced coastal warming by $25 \%$ and \\ controls its timing \\ - Ocean-atmosphere coupling in the \\ eastern-equatorial Atlantic triggers \\ coastal equatorward wind anomaly \\ that hastens the coastal event \\ demise
}

Supporting Information:

- Supporting information S1

Correspondence to:

S. Illig,

serena.illig@ird.fr

Citation:

Illig, S., Bachèlery, M.-L., \& Lübbecke, J. F. (2020). Why do Benguela Niños lead Atlantic Niños? Journal of Geophysical Research: Oceans, 125, e2019JC016003. https://doi.org/ 10.1029/2019JC016003

Received 20 DEC 2019 Accepted 13 AUG 2020 Accepted article online 18 AUG 2020

(C)2020. American Geophysical Union. All Rights Reserved.

\section{Why Do Benguela Niños Lead Atlantic Niños?}

\author{
Serena Illig, ${ }^{1,2}$, Marie-Lou Bachèlery ${ }^{2,3}$ (D), and Joke F. Lübbecke ${ }^{4,5}$ (D) \\ ${ }^{1}$ Laboratoire d'Etudes en Géophysique et Océanographie Spatiale (LEGOS), CNRS/IRD/UPS/CNES, Toulouse, France, \\ ${ }^{2}$ Department of Oceanography, MARE Institute, LMI ICEMASA, University of Cape Town, Cape Town, South Africa, \\ ${ }^{3}$ Nansen-Tutu Centre, Marine Research Institute, Department of Oceanography, University of Cape Town, Cape Town, \\ South Africa, ${ }^{4}$ Research Division Ocean Circulation and Climate Dynamics, GEOMAR Helmholtz Centre for Ocean \\ Research Kiel, Kiel, Germany, ${ }^{5}$ Faculty of Mathematics and Natural Sciences, Christian-Albrechts-Universität zu Kiel, \\ Kiel, Germany
}

\begin{abstract}
We investigate the lag between warm interannual Sea Surface Temperature (SST) events in the eastern-equatorial Atlantic, the Atlantic Niños, and the occurrence of Benguela Niños along the southwestern Angolan coast. While it is commonly agreed that both events are associated with equatorial and subsequent coastal-trapped wave propagations driven remotely by a relaxation of the trade-winds, it is surprising that SST anomalies off Angola tend to precede the ones in the eastern-equatorial sector by $\sim 1$ month. To explain this counterintuitive behavior, our methodology is based on the experimentation with a Tropical Atlantic Ocean model. Using idealized wind-stress perturbations from a composite analysis, we trigger warm equatorial and coastal events over a stationary and then, seasonally varying ocean mean-state. In agreement with the linear dynamics, our results show that when the interannual wind-stress forcing is restricted to the western-central equatorial Atlantic, the model yields equatorial events leading the coastal ones. This implies that neither the differences in the ocean stratification between the two regions (thermocline depths or modal wave contributions) nor the seasonal phasing of the events explains the observed temporal sequence. Only if wind-stress anomalies are also prescribed in the coastal fringe, the coastal warming precedes the eastern-equatorial SST anomaly peak, emphasizing the role of the local forcing in the phenology of Benguela Niños. A weaker South-Atlantic Anticyclone initiates the coastal warming before the development of eastern-equatorial SST anomalies. Then, equatorward coastal wind anomalies, driven by a convergent anomalous circulation located on the warm Atlantic Niño, stop the remotely forced coastal warming prematurely.
\end{abstract}

Plain Language Summary We investigate the Sea Surface Temperature (SST) interannual fluctuations in the Tropical Atlantic. We focus on the extreme warm events that occur every few years in the Gulf of Guinea, the Atlantic Niños, and along the coast of Angola-Namibia, the Benguela Niños. It is commonly agreed that both events are forced by equatorial and subsequent coastal waves triggered in the western-central basin by a relaxation of the trade-winds. Yet, we observe that the coastal warming tends to precede the one in the Gulf of Guinea by $\sim 1$ month. We explain this counterintuitive fact, using experimentation with a Tropical Atlantic Ocean model. Using idealized wind-stress perturbations, we simulate warm equatorial and coastal events on top of a stationary and then, seasonally varying ocean mean-state. Results show that when wind-stress perturbations are confined to the western-central equatorial Atlantic, the model yields equatorial events leading the coastal variability, consistent with the propagation path of the waves. This implies that neither the ocean mean-state nor its seasonal variability controls the timing between events. We further show that only when wind-stress anomalies are prescribed within the coastal fringe, warm events off Angola precede the eastern-equatorial SST anomaly. Both warmings originate from a reduction of the strength of the South-Atlantic Anticyclone. Nevertheless, local processes initiate the coastal warming before the remotely forced equatorial waves impact the eastern-equatorial SST. Benguela Niños then also stop earlier due to the development of coastal wind anomalies associated with a convergent anomalous circulation located on the warm Atlantic Niño event.

\section{Introduction}

The Sea Surface Temperature (SST) variability in the equatorial and southeastern Tropical Atlantic Ocean is dominated by the seasonal cycle (Burls et al., 2011; Ding et al., 2009; Xie \& Carton, 2004), most prominently associated with the formation of a cold tongue in the eastern-equatorial basin in late boreal spring 
(see, e.g., Cabos et al., 2019). The seasonal variation is modulated by variability at interannual time-scales (e.g., Xie \& Carton, 2004) which is phase-locked to the seasonal cycle. In the cold tongue region, there is a maximum in boreal summer (Keenlyside \& Latif, 2007) and a secondary minor peak in November-December (Okumura \& Xie, 2006). Interannual SST variability along the coast off Angola and Namibia tends to be highest in boreal spring, that is, during the warm season (Florenchie et al., 2004).

The interannual SST variability in the eastern-equatorial Atlantic and along the coast of Southwest Africa, illustrated in Figure 1a, has been described in terms of climate modes, namely, the Atlantic Niño mode focusing on the equatorial cold tongue variability (e.g., Carton \& Huang, 1994; Illig et al., 2006; Ruiz-Barradas et al., 2000; Servain et al., 2000; see Lübbecke et al., 2018 for a review) and the Benguela Niño highlighting the SST variations off Angola and Namibia (Florenchie et al., 2003; Shannon et al., 1986). During Atlantic Niño events, the SST in the cold tongue region can exceed the climatological value by up to $1.5^{\circ} \mathrm{C}$ with strong implications for the West African monsoon (Brandt et al., 2011; Mohino et al., 2011; Rodríguez-Fonseca et al., 2015). Benguela Niño events, which can reach SST Anomalies (SSTA) of $3^{\circ} \mathrm{C}$, can have severe impacts on local fisheries (Binet et al., 2001; Boyer et al., 2001) and the regional climate such as precipitation over southwestern Africa (Lutz et al., 2015; Rouault et al., 2003). As the two phenomena are highly correlated and linked via long equatorial and subsequent coastal wave propagations (Bachèlery et al., 2016; Florenchie et al., 2003; Imbol Koungue et al., 2017, 2019; Lübbecke et al., 2010; Rouault et al., 2007, 2018), it is debated whether they should actually be viewed as one single mode of variability.

The close connection between Atlantic and Benguela Niño events has been related to their forcing mechanism. While several processes have been shown to contribute to the SSTA in the eastern-equatorial Atlantic, most studies agree that eastward-propagating Equatorial Kelvin Waves (EKW) that are forced by interannual wind-stress fluctuations in the western-central part of the basin play an important role for the generation of the majority of Atlantic Niño events (see recent reviews by Cabos et al., 2019; Lübbecke et al., 2018). These EKWs are associated with changes in stratification and currents, allowing for less (more) effective vertical entrainment and thus leading to anomalous warm (cold) SST in the cold tongue region (Planton et al., 2018). Once the EKW reach the eastern boundary, a significant part of their energy is transmitted poleward along the African continent as Coastal Trapped Waves (CTW; Clarke, 1983; Moore, 1968). Similar to EKW, CTW can trigger substantial SST fluctuations off the Angolan and Namibian coasts, that is, Benguela Niños and Niñas (Bachèlery et al., 2016, 2020; Imbol Koungue et al., 2017, 2019; Rouault et al., 2007, 2018).

What is curious about the relationship between Atlantic and Benguela Niños is their time-lag. Even though the EKW first cross the equatorial cold tongue region before continuing their propagation to the Angola-Benguela Area (ABA; $\left[8^{\circ} \mathrm{E}\right.$-coast; $\left.10^{\circ} \mathrm{S}-20^{\circ} \mathrm{S}\right]$ ), Benguela Niños tend to lead Atlantic Niños by 1 to 3 months (Hu \& Huang, 2007; Lübbecke et al., 2010; Polo et al., 2008; Rouault et al., 2009). This is illustrated in Figure 1b, which presents a lag-correlation between the interannual SSTAs in the eastern-equatorial basin, averaged in the ATL3 domain $\left(\left[20^{\circ} \mathrm{W}-0^{\circ} \mathrm{E} ; 3^{\circ} \mathrm{S}-3^{\circ} \mathrm{N}\right]\right)$, and the coastal SSTA (averaged within the $2^{\circ}$-width coastal fringe and over $10^{\circ}$-length latitudinal windows). Coastal SSTAs close to the Equator lead the ones in the ATL3 region by about 2 weeks, and the lag increases with latitude to about 1.5 months south of the Angola Benguela Frontal Zone (ABFZ; $\left.17^{\circ} \mathrm{S}\right)$. Some hypotheses have been brought forward to explain this counter-intuitive timing between the occurrence of eastern-equatorial and Benguela warm events. Polo et al. (2008) proposed that the coastal warming originates from locally forced upwelling anomalies which are then spread to the cold tongue region via Rossby wave propagations. Hu and Huang (2007) suggested that a local SST anomaly in the ABA impacts the atmospheric circulation, thereby leading to westerly wind anomalies in the equatorial Atlantic that then causes warm anomalies there. Lübbecke et al. (2010) argued for the differences in the mean and seasonally varying thermocline depth in the two regions. As the mean thermocline depth is much deeper in the eastern-equatorial basin than in the ABA, they suggested that subsurface anomalies would require additional time to be lifted to the surface layer (by upwelling and vertical mixing) and affect the equatorial SST (cf. “upwelling pathway” described by Zelle et al., 2004). They also emphasized that the eastern-equatorial basin is only susceptible to EKW forcing in boreal summer when the thermocline is seasonally shallow and thus subsurface/surface coupling is at its maximum (Keenlyside \& Latif, 2007). Benguela Niños, on the other hand, tend to peak in boreal spring when the Angola-Benguela front is at its southernmost position. 
(a) OISST Composite SSTA $\left({ }^{\circ} \mathrm{C}\right)$

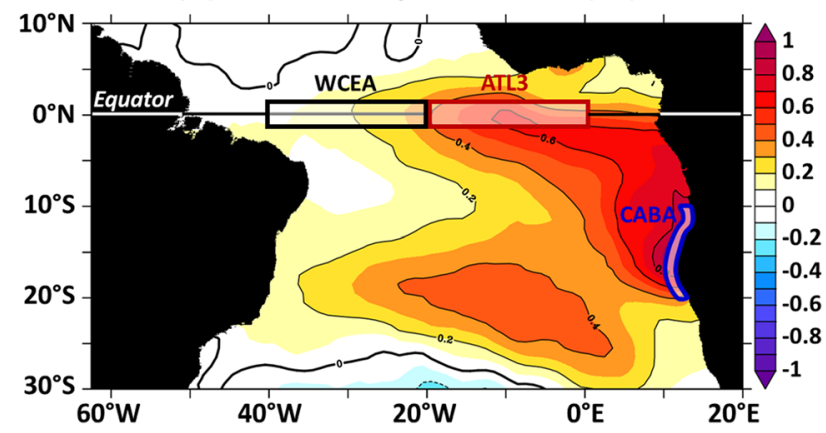

(b) OISST ATL3/coastal SSTA lag-correlation

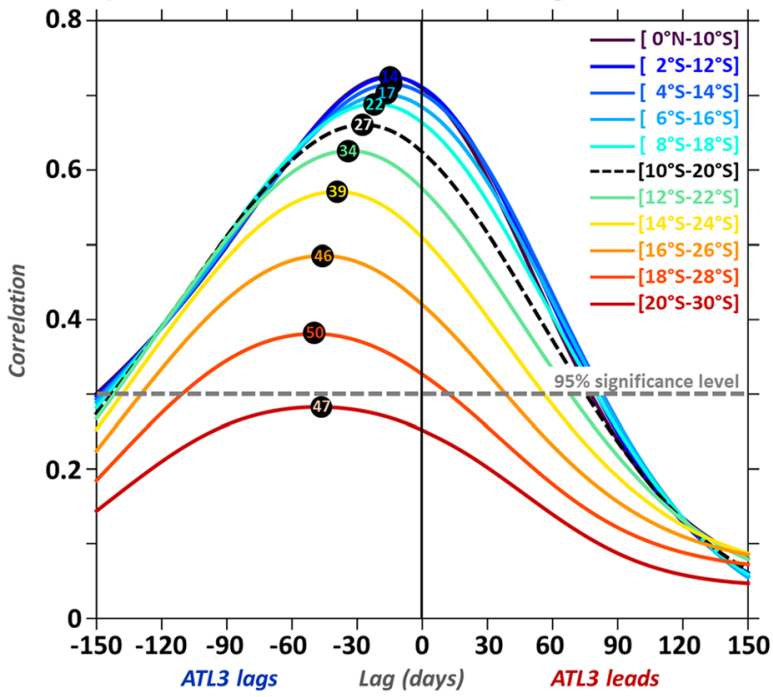

Figure 1. (a) Map of observed Tropical Atlantic SST interannual anomalies (SSTA, ${ }^{\circ} \mathrm{C}$ ) averaged for the 10 warmest events. This composite is estimated based on the highest peaks in the principal component of the first EOF (explaining $34 \%$ of the SSTA variance). (b) Lag between observed eastern-equatorial SSTA variability and observed SST interannual fluctuations along the southwestern coast of Africa: Correlation between the SSTA averaged within the ATL3 box $\left(20^{\circ} \mathrm{W}-0^{\circ} \mathrm{E} ; 3^{\circ} \mathrm{S}-3^{\circ} \mathrm{N}\right)$ and the coastal SSTA (averaged within $2^{\circ}$ from the coast and over $10^{\circ}$ latitudinal windows) as a function of the lag (in days). Positive lags indicate that the equatorial variability leads the coastal fluctuations. Colors of the curves indicate the latitudinal extension over which the data are averaged as listed in the top right corner. The black dashed line represents the CABA domain. Numbers within black discs indicate the lag (in days) at which the correlation is maximum. The horizontal gray dashed line denotes the limit of the $95 \%$ significance level for the correlation (Sciremammano, 1979). Both analyses are performed with the weekly OISST observations over the 1982-2015 period.

Recently, the relative role of the different baroclinic modes of the waves has been discussed with respect to the timing of Sea Level (SL) fluctuations along the coast (Bachèlery et al., 2020). While the second baroclinic mode dominates the interannual signal in the eastern-equatorial Atlantic (Illig et al., 2004, 2006; Imbol Koungue et al., 2017), recent results stress the importance of the less dissipative first mode along the southwestern African coast (Bachèlery et al., 2020). As the first EKW-CTW mode is faster than the second one, a dominance of the equatorially forced first mode can allow signals to reach areas in the south before the second mode contribution arrives further north. This could in particular explain the decreasing lags for latitude bands south of $20^{\circ} \mathrm{S}$ in Figure 1.

Several studies have also highlighted the importance of the subtropical high-pressure system, the South-Atlantic Anticyclone (SAA), for generating both wind anomalies in the western-to-central equatorial Atlantic, where they can excite EKW, and along the coast of southwestern Africa (Bachèlery et al., 2016; Imbol Koungue et al., 2019; Lübbecke et al., 2010, 2014; Martín-Rey et al., 2018; Richter et al., 2010). 
Along-shore wind-stress and wind-stress curl anomalies at the coast can trigger locally forced CTW which modulate the magnitude of the local upwelling, lead to alongshore current and latent heat flux fluctuations, and thereby impact coastal SSTAs (Lübbecke et al., 2019). Both local and remote equatorial forcing of Benguela Niño events can thus be attributed to the SAA forcing.

In this study, we want to revisit the question why Benguela Niños tend to lead Atlantic Niño events. Using a Tropical Atlantic Ocean model and performing targeted sensitivity experiments, we test the hypotheses that were put forward in previous studies, in particular the role of the differences in ocean mean-states between the two regions, the seasonality of the thermocline depth, and the role of local wind-stress anomalies. The paper is structured as follows: In section 2, observational data sets, the method to compute interannual anomalies, and key regions are presented. Section 3 introduces the Tropical Atlantic regional ocean model configuration. The methodology and the idealized model experiment carried out are detailed in section 4 . Section 5 presents the results, while section 6 provides a discussion, followed by concluding remarks and perspectives to this work.

\section{Data Sets, Interannual Anomalies, and Key Regions}

Observed pattern and time evolution of interannual SSTA (presented in Figure 1) are described using NOAA's Optimum Interpolation Sea Surface Temperature. We used the $0.25^{\circ} \times 0.25^{\circ}$ daily global analysis product blended with AVHRR data (OISST version 2, also known as Reynolds_AVHRR'SST, Reynolds et al., 2007) from 1982 to 2015. The product merges SST observations from remote-sensed AVHRR observations and in situ platforms (ships and buoys). The latter are interpolated and extrapolated using Optimal Interpolation at the NOAA National Centers for Environmental Information.

The DRAKKAR Forcing Set (DFS) v5.2 (Dussin et al., 2016) surface winds, temperature and humidity fields, along with surface heat/fresh-water fluxes (longwave and shortwave radiations and precipitation rate) provide an interannual forcing for our ocean model configuration (cf. section 3). The DFS5.2 data set has been built by combining ERA40 (1958-1978) and ERA-Interim (1979-2015) atmospheric reanalysis (Dee et al., 2011) with applied corrections on temperature, wind fields as well as heat and water fluxes using observed data sets, satellite-based products, and global ORCA ocean model configurations. Three hourly wind fields and daily longwave and shortwave radiation and precipitation fields were acquired from 1958 to 2015 at a horizontal resolution of $0.7^{\circ} \times 0.7^{\circ}$. For consistency, we concatenated ERA40 and ERA-Interim 6-hourly mean Sea Level Pressure (SLP) and winds to describe the Tropical Atlantic surface circulation and estimate the position and amplitude of the SAA (Figure 13).

Interannual fluctuations are estimated as in Mosquera-Vásquez et al. (2014) and Bachèlery et al. (2016). First, timeseries are linearly detrended, and monthly averages are computed. The monthly climatology is then subtracted, and the subseasonal fluctuations are removed using a 1-2-1 running weighted average. At last, the timeseries are reinterpolated onto their original temporal resolution using cubic splines.

In this paper, we use key regions to quantify the interannual SST and SL equatorial and coastal variabilities. The ATL3 region $\left(\left[20^{\circ} \mathrm{W}-0^{\circ} \mathrm{E} ; 3^{\circ} \mathrm{S}-3^{\circ} \mathrm{N}\right]\right.$, cf. the red rectangle in Figure 1a) was first defined in Zebiak (1993) to describe the Atlantic Niño dynamics. Our Kelvin-ATL3 (KATL3) domain $\left(\left[20^{\circ} \mathrm{W}-0^{\circ} \mathrm{E} ; 1^{\circ} \mathrm{S}-1^{\circ} \mathrm{N}\right]\right)$ resembles the ATL3 region but is more confined to the Equator to better capture the equatorially trapped contributions of the EKW on the SL fluctuations. Similarly, the Coastal Angola Benguela Area (CABA) box is defined with respect to the Angola-Benguela Area (ABA, $\left[8^{\circ} \mathrm{E}-\right.$ coast; $\left.10^{\circ} \mathrm{S}-20^{\circ} \mathrm{S}\right]$ ) of Florenchie et al. (2003), but it is narrowed on the $2^{\circ}$-width coastal fringe (cf. the blue coastal region delineated in Figure 1a). The remote forcing in the western-central equatorial Atlantic is quantified by averaging the zonal wind-stress anomalies within the Western-Central Equatorial Area (WCEA, $\left[40^{\circ} \mathrm{W}-20^{\circ} \mathrm{W} ; 3^{\circ} \mathrm{S}-3^{\circ} \mathrm{N}\right]$, cf.the black rectangle in Figure 1a).

\section{The Regional Ocean Model Configuration}

We designed a Tropical Atlantic Ocean model configuration using the Coastal and Regional Ocean COmmunity model (CROCO; Debreu et al., 2012; Penven et al., 2006; Shchepetkin \& McWilliams, 2005; http://www.croco-ocean.org). CROCO solves the three-dimensional Navier-Stokes primitive equations using finite-difference approximations on a horizontal curvilinear Arakawa $\mathrm{C}$ grid and on a vertical 


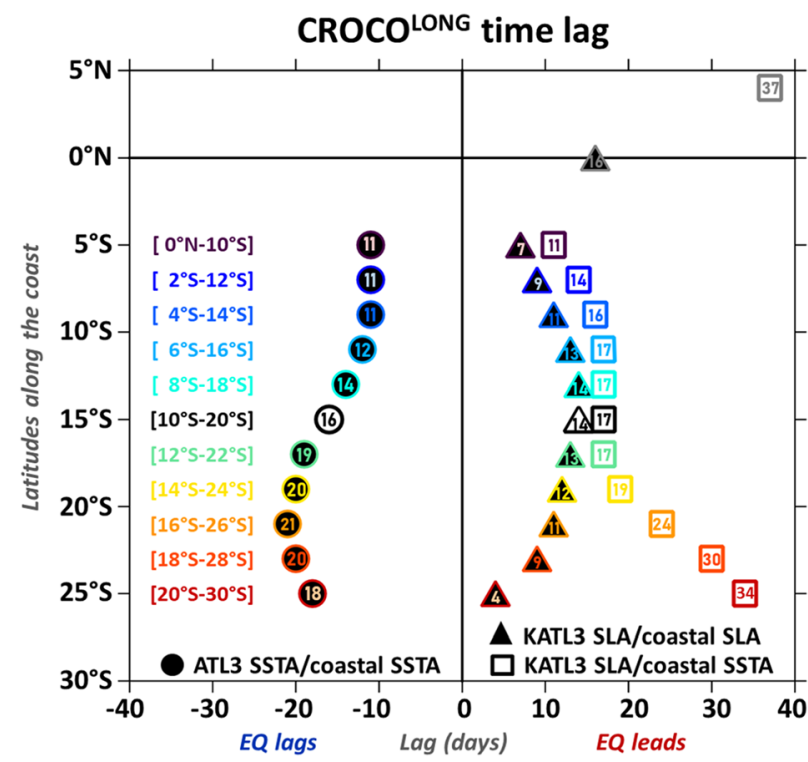

Figure 2. Lag of maximum correlation between equatorial and coastal variabilities simulated in $\mathrm{CROCO}^{\mathrm{LONG}}$ as a function of the latitude. Colors indicate the latitudinal extension over which the coastal data are averaged. Black symbols represent the CABA domain. Circles show the lag associated with the maximum-correlation between ATL3 SSTA and coastal SSTA (averaged within $2^{\circ}$ from the coast and over $10^{\circ}$ latitudinal windows). Triangles represents the lag between KATL3 SLA and coastal SLA. Gray triangle at $\left(0^{\circ} \mathrm{N},+16\right.$ days $)$ indicates the lag of the maximum correlation between KATL3 SLA and ATL3 SLA. Squares show the lag between the KATL3 SLA and coastal SSTA. Gray square at ( $4^{\circ} \mathrm{N} ;+37$ days) reveals the lag of the maximum correlation between KATL3 SLA and SSTA averaged within $\left(20^{\circ} \mathrm{W}-0^{\circ} \mathrm{S}, 3^{\circ} \mathrm{N}-5^{\circ} \mathrm{N}\right)$. To compare with Figure 1 , analyses are performed over 1982-2015. stretched terrain-following coordinate system. The parametrizations and the physical parameters we used are similar to the one of Bachèlery et al. (2020). The regional grid extends from $30^{\circ} \mathrm{S}$ to $10^{\circ} \mathrm{N}$, spanning the Tropical Atlantic basin from the eastern coast of South America to the western coast of Africa (Figure 1a). The configuration is developed at an eddy-resolving resolution of $1 / 12^{\circ}$, with 37 terrain-following vertical levels stretched near the surface. The bathymetry is derived from GEBCO_08 global elevation database at 30 arc-second spatial resolution (http://www.gebco.net). Initial and lateral conditions at the northern and southern open boundaries are estimated using the CARS2009 climatology (Dunn, 2009; Ridgway et al., 2002). As no river discharge fluxes are explicitly taken into account, the model Sea Surface Salinity (SSS) is restored to the CARS2009 monthly climatological SSS with increased coefficients within the coastal fringes. For all experiments performed in this study, there is no restoring to observed SST, but the specification of atmospheric conditions through turbulent heat fluxes bulk formulae damps the SST towards prescribed air temperature values.

In order to validate our model configuration, a realistic simulation $\left(\mathrm{CROCO}^{\mathrm{LONG}}\right)$ was first forced by surface momentum, heat, and freshwater fluxes estimated with bulk formulae (Kondo, 1975) using daily averages of the DFS surface winds, temperature, and humidity at $2 \mathrm{~m}$, precipitations, solar, and long-wave fluxes. The model solution reached a statistical equilibrium after 5 years of spin-up performed by forcing the model with monthly climatological forcing estimated over the 19581962 period. Then, CROCO ${ }^{\text {LONG }}$ simulation was run over the 58 years spanning the 1958-2015 period, during which 3-day averages of model surface wind-stress and state variables (temperature, salinity, currents, and sea-level) were stored.

We performed a validation, focusing on the quantities that control the ocean dynamics in the eastern-equatorial sector and along the coast of southwestern Africa (cf. supporting information). Despite a typical deeper and too diffuse thermocline, comparisons of $\mathrm{CROCO}^{\mathrm{LONG}}$ outputs with available subsurface observations indicate that the model simulates a realistic mean-state and seasonal variability which controls the modal structures and characteristics of the equatorial and coastal waves. The interannual variability of SST and SL is in very good agreement with remote-sensed observations, both in terms of magnitude and phasing (correlation). Of particular interest in this study is how $\mathrm{CROCO}^{\mathrm{LONG}}$ simulates the delay between the variabilities in the cold tongue region and along the coast of southwestern Africa. This is illustrated in Figure 2. The analysis of the Sea Level interannual Anomalies (SLA, triangles in Figure 2) shows that CROCO ${ }^{\text {LONG }}$ coastal variability follows the SL fluctuations in the eastern-equatorial region. The results nicely portray the concave banana-shaped pattern described in Bachèlery et al. (2020), in which equatorially forced CTW fluctuations in the southern Benguela peak before the waves imprint the variability off Angola. The latter is associated with the alternation of CTW modal contributions: fast first mode in the Benguela upwelling system and slower second and third modes in the North (Bachèlery et al., 2020). As far as the SSTA are concerned (cf. circles in Figures 2 and S4) our regional model nicely mimics the observations (Figure 1a), with coastal SSTA variability preceding the SSTA fluctuations in the ATL3 box (negative lags). Notably, the lags are shorter than the estimations obtained with the observations. For instance, the lag-correlation analysis between ATL3 and CABA observed SSTA showed a delay of 27 days, while the lag in CROCO ${ }^{\text {LONG }}$ is only 16 days, ATL3 leading the coastal variability. This discrepancy is most likely due to the identified biases in the model mean-state and to the coarse resolution of the coastal wind forcing that does not represent the wind drop-off zone. However, this value, obtained with our most realistic simulation, has to be kept in mind when interpreting the solutions of our idealized model experiments. 
The realism of CROCO ${ }^{\text {LONG }}$ outputs and the simulated time-sequence between equatorial and coastal interannual fluctuations gives confidence to use this model configuration to uncover why Benguela Niño events tend to precede the development Atlantic Niños. This will be done in the following section through targeted model experiments.

\section{Methodology and Idealized Model Experiments}

In order to pinpoint the processes responsible for the unexpected timing of Atlantic and Benguela Niño events, we conduct a series of targeted model experiments in which warm events are triggered by idealized wind-stress anomalies over various constrained ocean mean conditions. This forcing is created by identifying intense warm events in the $\mathrm{CROCO}^{\mathrm{LONG}}$ simulation and then performing a composite analysis of the model wind-stress interannual anomalies.

\subsection{Composite Analysis and Idealized Wind-Stress Perturbations}

We first compute the CROCO ${ }^{\text {LONG }}$ interannual SST anomalies averaged in the ATL3 region (Figure 3) over the 1958-2015 period. Its decadal contribution is isolated using a low-pass Fast Fourier Transform (FFT) filter with a cutoff frequency of 10 year $^{-1}$. Then, strong interannual warm events are identified as times when ATL3 SSTA exceeds 1.5 times the STandard Deviation (STD) above the decadal fluctuations (orange dashed line in Figure 3). Following this criterion, 15 warm equatorial events are identified (red dots in Figure 3). As the ATL3 SSTA index is highly correlated with the first principal component of SSTA encompassing the cold tongue region and the southeastern Atlantic (Lübbecke et al., 2018), each of the eastern-equatorial events we have identified is associated with positive interannual SST variations off Angola (cf. blue line in Figure 3 and section 5.1).

Composites are then computed by averaging CROCO ${ }^{\text {LONG }}$ SST, SL, and wind-stress interannual anomalies at the peak phase of the identified warm events and every 3 days between -120 and +120 days around the peak. To document the atmospheric circulation, composites of ERA40 and ERA-Interim daily SLP and winds are also calculated. Note that the decadal variability is primarily filtered out by subtracting the decadal contribution (using a 10 year $^{-1}$ low-pass FFT filter). The resulting zonal and meridional wind-stress anomalies will constitute an idealized surface forcing that will be applied over various chosen ocean mean-states in order to trigger anomalous EKW and subsequent CTW propagations. This forcing will be described in section 5.1 (cf. Figures 4 and 5a).

\subsection{Model Experimentation}

As stated in the introduction, the scientific community mainly agrees that the majority of the Atlantic and Benguela Niños are associated with the propagation of planetary waves, triggered remotely by wind-stress fluctuations in the western-central equatorial Atlantic. On that basis, the counterintuitive fact that SST anomalies off Angola precede equatorial interannual SST fluctuations could be explained by the differences in the ocean stratification between the two regions, namely, the thermocline depth (Lübbecke et al., 2010) or the distinct modal wave contributions (Bachèlery et al., 2020). Also, the different seasonality of the interannual SST variability (Lübbecke et al., 2018) or the impact of the coastal atmospheric interannual fluctuations (Bachèlery et al., 2016; Richter et al., 2013) can influence the timing of the events. To test these processes, we

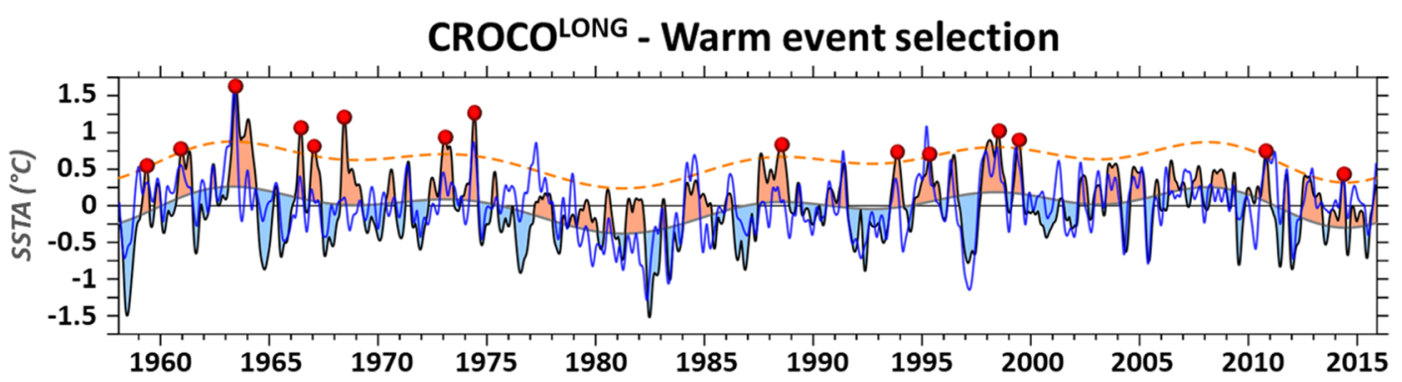

Figure 3. Timeseries CROCO ${ }^{\text {LONG }}$ interannual SST anomalies $\left({ }^{\circ} \mathrm{C}\right.$ ) averaged in the ATL3 box (black line) and its decadal fluctuations (gray line). The orange dashed line is the threshold used to define warm event occurrences (see section 4.1) and the red dots highlight the peak of the 15 events identified. The blue line shows CROCO ${ }^{\text {LONG }} \mathrm{CABA}$ interannual SSTA. 
Table 1

First Set of Model Experiments: Name, Period/Duration, Number of Ensemble Experiments, Type of Surface Boundary Forcing and Idealized Zonal Wind-Stress Anomalies

\begin{tabular}{lcccc}
\hline Simulation name & Period or duration & Nb ensemble experiments & Surface forcing & Idealized WSA \\
\hline $\mathrm{CROCO}^{\text {LONG }}$ & $1958-2015$ & $\times$ & Daily interannual & $\times$ \\
\hline$\overline{\mathrm{EXP}}$ & 12 months & 10 & $1958-2015$ mean & $\times$ \\
$\overline{\mathrm{EXP}}^{W}$ & 12 months & 10 & $1958-2015$ mean & $\mathrm{COMPO}^{\mathrm{W}}$ \\
$\overline{\mathrm{EXP}}^{A}$ & 12 months & 10 & $1958-2015$ mean & $\mathrm{COMPO}^{\mathrm{A}}$ \\
\hline
\end{tabular}

develop a series of model sensitivity experiments in idealized conditions (Tables 1 and 2) and analyze the phenology of simulated anomalous warm events in both regions. After a 5-year spin-up period, all these simulations are run for 12 months, which is shown to be sufficient to simulate the development and the demise of the warm events in both regions. Note that, unlike in the CROCO ${ }^{\text {LONG }}$ configuration in which wind-stress forcing was computed using bulk formulae, the idealized simulations are forced by the surface momentum stress from CROCO ${ }^{\text {LONG }}$ simulation (mean-state and anomalous perturbations). This allows controlling the model forcing and thus avoiding any nonlinearities associated with the bulk formulae.

In the first series of experiments (Table 1), the model is maintained in a permanently constrained mean-state without any seasonal variability. CROCO is thus forced at its boundaries by stationary OBC (annual averages of the CARS2009 climatology) and mean atmospheric forcing for heat, fresh-water, and momentum surface fluxes (DFS and CROCO ${ }^{\text {LONG }}$ fields averaged over 1958-2015). In this framework, we will be able to evaluate the role of the ocean mean conditions on the phasing of the warm events in both regions, independently from the seasonal variations of the ocean stratification and circulation. In the $\overline{\mathrm{EXP}}^{W}$ experiment, anomalous warm events are triggered by the wind-stress perturbations derived from the composite analysis (cf. section 4.1) during the [peak -90 days/peak +90 days] period and restricted to the western-central equatorial Atlantic sector $\left(\mathrm{COMPO}^{\mathrm{W}}\right.$ domain, cf. green rectangle in Figure $\left.4 \mathrm{~b}\right)$. Note that, to reduce spurious wind-stress curl, a gradual (linear) $5^{\circ}$-width transition zone is appended south and east of the COMPO ${ }^{\mathrm{W}}$ domain between the region where perturbations are prescribed and the region where no wind-stress

Table 2

Same as Table 1, for the Second Set of Model Experiments

\begin{tabular}{|c|c|c|c|c|}
\hline $\begin{array}{l}\text { Simulation } \\
\text { name }\end{array}$ & Duration & $\begin{array}{l}\mathrm{Nb} \text { ensemble } \\
\text { experiments }\end{array}$ & $\begin{array}{l}\text { Surface } \\
\text { forcing }\end{array}$ & Idealized WSA \\
\hline$\widetilde{\mathrm{EXP}}$ & 24 months & 10 & $\begin{array}{l}\text { 1958-2015 monthly } \\
\text { climatology }\end{array}$ & $x$ \\
\hline$\widetilde{\operatorname{EXP}}^{\mathrm{W}} 01$ & & & & $\mathrm{COMPO}^{\mathrm{W}}$ peaking in JAN \\
\hline$\widetilde{\mathrm{EXP}}^{\mathrm{W}} 02$ & & & & $\mathrm{COMPO}^{\mathrm{W}}$ peaking in FEB \\
\hline $\begin{array}{c}\vdots \\
\sim_{\mathrm{W}}\end{array}$ & 12 months & 10 & $\begin{array}{l}\text { 1958-2015 monthly } \\
\text { climatology }\end{array}$ & $\begin{array}{l}\vdots \\
\mathrm{w}\end{array}$ \\
\hline$\widehat{\operatorname{EXP}}^{w} 11$ & & & & $\mathrm{COMPO}^{\mathrm{W}}$ peaking in $\mathrm{NOV}$ \\
\hline$\widetilde{\operatorname{EXP}}^{\mathrm{W}} 12$ & & & & $\mathrm{COMPO}^{\mathrm{W}}$ peaking in $\mathrm{DEC}$ \\
\hline$\widetilde{\mathrm{EXP}}^{A} 01$ & & & & $\mathrm{COMPO}^{\mathrm{A}}$ peaking in JAN \\
\hline$\widetilde{\mathrm{EXP}}^{A} 02$ & & & & $\mathrm{COMPO}^{\mathrm{A}}$ peaking in FEB \\
\hline$\vdots$ & 12 months & 10 & $\begin{array}{l}\text { 1958-2015 monthly } \\
\text { climatology }\end{array}$ & $\vdots$ \\
\hline$\widetilde{\mathrm{EXP}}^{A} 11$ & & & & $\mathrm{COMPO}^{\mathrm{A}}$ peaking in NOV \\
\hline$\widetilde{\mathrm{EXP}}^{A} 12$ & & & & $\mathrm{COMPO}^{\mathrm{A}}$ peaking in $\mathrm{DEC}$ \\
\hline
\end{tabular}


anomalies are imposed. $\overline{\mathrm{EXP}}^{A}$ experiment differs from $\overline{\mathrm{EXP}}^{W}$ because anomalous wind-stress forcing is applied over the whole model domain and in particular along the coast of West Africa $\left(\mathrm{COMPO}^{\mathrm{A}}\right.$ domain, cf. orange rectangle in Figure $4 \mathrm{~b}$ ). The unperturbed $\overline{\mathrm{EXP}}$ simulation allows to ascertain the model mean-state in order to estimate $\overline{\mathrm{EXP}}^{W}$ and $\overline{\mathrm{EXP}}^{A}$ anomalies Tables 1.

In the second set of experiments (Table 2), we test the impact of the seasonally varying ocean state on the timing of the anomalous equatorial and coastal events. To do so, the model undergoes a monthly seasonal variability, which is achieved by prescribing monthly climatological Open Boundary Conditions (OBC) from CARS2009 climatology and surface conditions (heat, fresh-water, and momentum fluxes from DFS and CROCO $^{\text {LONG }}$ monthly climatologies estimated over 1958-2015). Anomalous wind-stress perturbations are applied successively such as the zonal wind-stress anomalies averaged in the western-central Atlantic (WCEA, $\left[40^{\circ} \mathrm{W}-20^{\circ} \mathrm{W} ; 3^{\circ} \mathrm{S}-3^{\circ} \mathrm{N}\right]$ ) peak at each calendar month, therefore forming a series of 12 experiments. For instance, in $\widetilde{\text { EXP01 }}(\widetilde{\mathrm{EXP}} 04)$ experiments, the maximum in zonal wind-stress anomalies happens in mid-January (mid-April). Also, similar to the first series of experiments, in the $\widetilde{\mathrm{EXP}}^{W}$ set of experiments, the wind-stress perturbations are restricted to the western-central equatorial Atlantic sector $\left(\mathrm{COMPO}^{\mathrm{W}}\right.$ domain), whereas in $\widetilde{\mathrm{EXP}}^{A}$ set of experiments the wind-stress anomalies extend over the whole model domain (COMPO${ }^{\mathrm{A}}$ domain). $\widetilde{\mathrm{EXP}}^{W}$ and $\widetilde{\mathrm{EXP}}^{A}$ anomalies are estimated relative to the seasonal mean-state simulated by the unperturbed experiment $\widetilde{\mathrm{EXP}}$ Table 2.

\subsection{Ensemble Simulations}

Because of the relatively high resolution of the model $\left(1 / 12^{\circ}\right)$, the nonlinear mesoscale variability (eddies, filaments, fronts ...) yields an intrinsic variability that can affect the linear dynamics (modal contribution, speed of the waves, modal scattering) and thermodynamic processes. The latter imprints on SLA and SST and can modulate the timing and amplitude of the simulated equatorial and coastal events. In order to smooth-out the model intrinsic nonlinearities, ensemble simulations of 10 members are produced for each idealized experiment conducted in this study. To do so, we perturb the model temperature at the end of the fourth year of spin-up using normally distributed random values with an STD of $10^{-2 \circ} \mathrm{C}$.

\section{Results}

\subsection{Composite Analysis and Idealized Wind-Stress Forcing}

To simulate anomalous warm events in the eastern-equatorial Atlantic and along the southwestern African coast via remote wave dynamics and local fluctuations, we created idealized wind-stress perturbations from a composite analysis of CROCO ${ }^{\text {LONG }}$ outputs (section 4.1). Over 1958-2015, 15 interannual equatorial warm events are identified from the analysis of the ATL3 SSTA timeseries (red dot in Figure 3), of which 10 peak in the May-June-July (MJJ) season (1959, 1963, 1966, 1968, 1974, 1988, 1995, 1998, 1999, 2014). The five remaining events occur in December 1960, January 1967, January 1973, November 1993, and October 2010, respectively. The events occurring in 1963, 1966, 1968, 1973, 1974, 1988, and 1995 are well known Atlantic Niño events that have been identified by several previous studies (Carton \& Huang, 1994; Lübbecke et al., 2010; Richter et al., 2013). The 1998 SSTA has been described as a noncanonical event by Richter et al. (2013).

The SSTA composite of the 15 events at the peak phase is presented in Figure $4 \mathrm{e}$ with color shading. It portrays a warming $\left(>1^{\circ} \mathrm{C}\right)$ of the equatorial band $\left(\left[7^{\circ} \mathrm{S}-4^{\circ} \mathrm{N}\right]\right)$ East of $30^{\circ} \mathrm{W}$ and maximum around $10^{\circ} \mathrm{W}$. All of the equatorial warm events are associated with local peaks in the SSTA off Angola (Figure 3), including the strong (1959, 1960, 1963, 1974, 1995, 1998, 2010) and moderate (1993, 1999) Benguela Niño events identified by Imbol Koungue et al. (2019). As a result, the equatorial warming extends southward along the southwestern African coast (Figure 4e), with a peak in the $\mathrm{ABFZ}\left(>1^{\circ} \mathrm{C}\right)$. The temporal evolution of the composite confirms that the coastal warming reaches its maximum before the SSTA peaks in the equatorial sector (Figure $4 \mathrm{a})$. SSTA averaged in the CABA peaks $\left(0.95^{\circ} \mathrm{C}\right) 24$ days before the maximum in ATL3 SSTA $\left(+0.83^{\circ} \mathrm{C}\right)$.

The peak warming in the eastern-equatorial and coastal domains is concomitant with an increased SLA in the Gulf of Guinea and along the southwestern coast of Africa. Before the peak phase, the SLA nicely resembles the signature of a downwelling equatorially trapped Kelvin wave, with positive SLA confined 
(a) CROCO ${ }^{\text {LONG }}$ composite

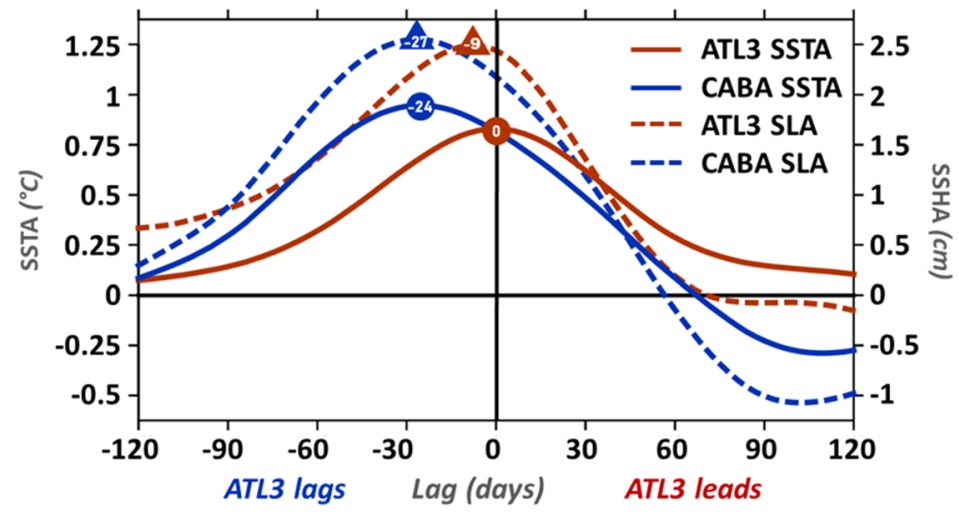

(b) CROCO ${ }^{\text {LONG }}$ composite $t=-90$ days
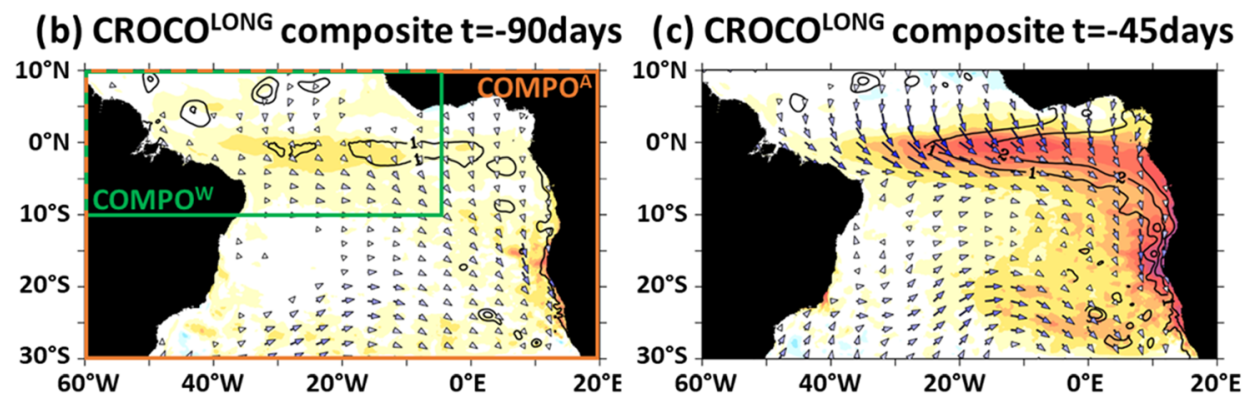

(d) CROCO ${ }^{\text {LONG }}$ composite $\mathrm{t}=-\mathbf{1 5}$ days

(e) CROCO ${ }^{\text {LONG }}$ composite $\mathrm{t}=0$ days
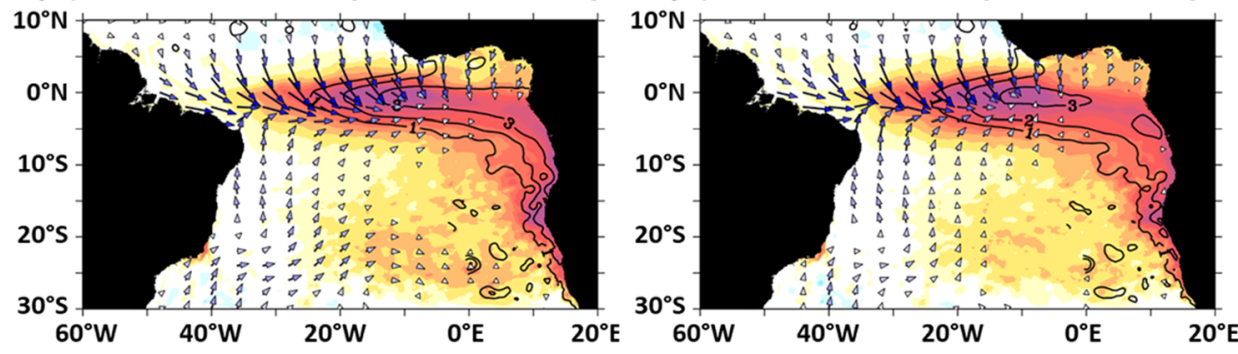

(f) CROCO ${ }^{\text {LONG }}$ composite $\mathrm{t}=+15$ days

(g) CROCO ${ }^{\text {LONG }}$ composite $\mathrm{t}=+45$ days
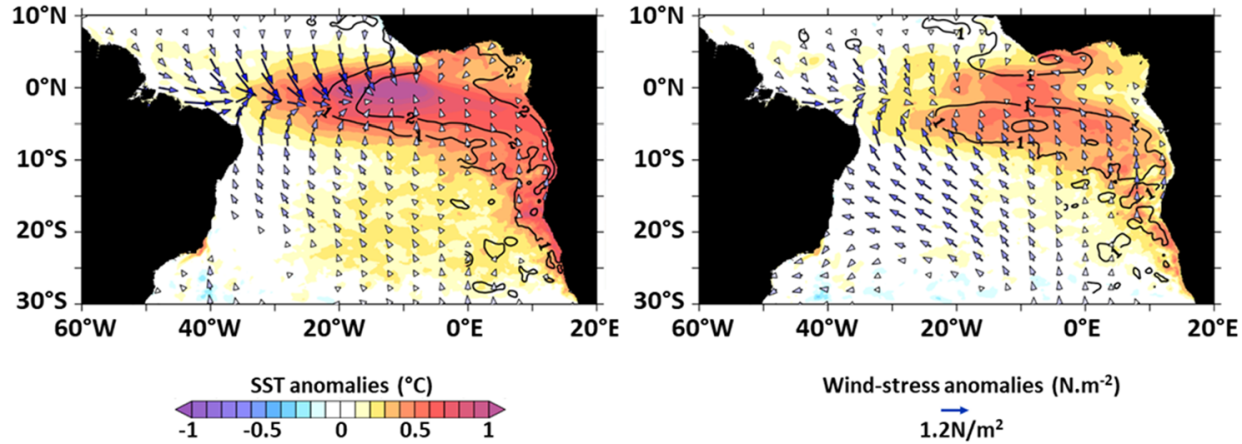

Wind-stress anomalies (N. $\left.\mathrm{m}^{-2}\right)$ $1.2 \mathrm{~N} / \mathrm{m}^{2}$

Figure 4. Composites warm events simulated in the $\mathrm{CROCO}^{\mathrm{LONG}}$ : (a) red and blue plain (dashed) lines show ATL3 and CABA interannual SST (SLA) composite timeseries, respectively, in function of the lag (days). Numbers within the discs (triangles) indicate the lag at which the anomalies are maximum. Negative lags indicate that SSTA and SLA fluctuations occur before the peak in ATL3 SSTA. (b-g) Composite maps at peak -90 days, peak -45 days, peak -15 days, peak phase, peak +15 days, peak +45 days: Color shading shows the SSTA $\left({ }^{\circ} \mathrm{C}\right)$, black iso-contours depict the $+1,+2,+3 \mathrm{~cm}$ SLA, and blue shaded arrows display wind-stress anomalies larger than $0.2 \mathrm{~N} . \mathrm{m}^{-2}$. Green and orange rectangles in panel (b) delineate the $\mathrm{COMPO}^{\mathrm{W}}$ and $\mathrm{COMPO}^{\mathrm{A}}$ domains (cf. section 4.2). A video disclosing additional frames of the time-lagged composites is provided in supporting information. 
within $\left[5^{\circ} \mathrm{S}-5^{\circ} \mathrm{N}\right]$ (contours in Figures $4 \mathrm{c}-4 \mathrm{e}$ ). After the peak phase (Figures $4 \mathrm{f}$ and $4 \mathrm{~g}$ ), the SLA widens on both sides of the Equator to reveal two SLA maxima nearly symmetric about the Equator and centered around $4^{\circ}$ and $5^{\circ}$ of latitude away from the equator. This evolution is typical of EKW reflection and westward propagation of equatorial Rossby waves. Off Angola, the SLA is maximum at the coast and its amplitude decreases off-shore, consistent with CTW propagations. The analysis of the SLA composite in the CABA and ATL3 boxes also shows that the SL elevation off Angola $(+2.5 \mathrm{~cm})$ precedes the one in the cold tongue region $(+2.5 \mathrm{~cm}$ ) by 18 days (Figure $4 \mathrm{a}$ ). This delay could be consistent with a possible contribution of the fast first CTW mode off Angola that would reach the CABA before the dominant second EKW mode at the Equator imprints the variability there (Illig \& Bachèlery, 2019). However, this sequence is not in agreement with the lag-correlation analysis between CROCO ${ }^{\text {LONG }}$ ATL3 and CABA SLA timeseries presented in Figure 2 (cf. black triangle) or the timing presented in Bachèlery et al. (2020) (Equatorial SLA leading coastal SLA off Angola by 10 days, cf. their Figure 7). This discrepancy will be discussed in section 6, in the light of the results obtained with the model sensitivity experiments. Note that a video disclosing additional frames of the time-lagged composites is provided in the supporting information.

Composites of interannual wind-stress anomalies (arrows in Figures $4 \mathrm{~b}-4 \mathrm{~g}$ ) show that these SST and SL anomalies are accompanied by north-westerly surface wind-stress anomalies in the western-central equatorial basin (West of $5^{\circ} \mathrm{W}$ ). In agreement with a remote forcing mechanism associated with the propagation of downwelling long equatorial waves, the relaxation of the trade winds develops prior to the peak of the event (Figures 4b-4d). These results are also in agreement with Imbol Koungue et al. (2019) and Lübbecke et al. (2010), who analyzed composites of Benguela Niño events. The zonal wind-stress anomaly averaged within WCEA is maximum $\left(1.04 \times 10^{-2} \mathrm{~N} . \mathrm{m}^{-2}\right.$, cf. Figure 5a) 15 days before the SSTA peaks in the ATL3 box (Figure $4 d$ ). It starts $\sim 3$ months before the peak phase of the event (Figure $4 \mathrm{~b}$ ) and is concomitant with an early warming of the equatorial band West of $10^{\circ} \mathrm{W}$. We isolated this interannual momentum flux forcing over the COMPO ${ }^{\mathrm{W}}$ domain $\left(\left[60^{\circ} \mathrm{W}-5^{\circ} \mathrm{W} ; 10^{\circ} \mathrm{S}-10^{\circ} \mathrm{N}\right]\right.$, cf. green rectangle in Figure $\left.4 \mathrm{~b}\right)$ during the [peak -90 days/peak +90 days] period. Simulations using this idealized interannual forcing will allow us to estimate the lag between the eastern-equatorial warming and the coastal warming off Angola and thus test the hypotheses in line with a remote forcing mechanism (see sections 5.2 and 5.3).

Wind-stress composites also highlight an anomalous circulation along the African continent. Downwelling-favorable northerly wind-stress anomalies blow along the coast, starting 120 days before the peak of the event. The deceleration of the equatorward surface wind-stress averaged in the CABA domain is maximum $\left(\tau_{y} \mathrm{~A}=-0.59 \times 10^{-2} \mathrm{~N}^{-\mathrm{m}^{-2}}\right) 2$ months before the peak in ATL3 SSTA. The temporal evolution of the composite further portrays a reverse in the coastal meridional wind-stress anomalies at peak -15 days (Figure $4 \mathrm{~d}$ ), followed by a moderate $\left(\tau_{y} \mathrm{~A} \sim 0.4 \times 10^{-2} \mathrm{~N} . \mathrm{m}^{-2}\right)$ acceleration of the southerly meridional windstress. To quantify the role of the coastal wind-stress interannual modulation, a second series of experiments are conducted in which the composited wind-stress perturbation forcing is extended over the whole model domain and in particular along the coast of southwestern Africa $\left(\mathrm{COMPO}^{\mathrm{A}}\right.$ domain, cf. green rectangle in Figure 4b). Results are presented in section 5.4.

\subsection{Model Output Analysis: Warm Events in a Steady Ocean Mean-State}

We first investigate if the differences in the mean ocean stratification between the equatorial and the coastal regions can explain the timing between the equatorial and the coastal SSTA fluctuations, assuming that both warmings are triggered remotely by a relaxation of the trade winds in the western-central equatorial Atlantic. We analyze the outputs of $\overline{\mathrm{EXP}}^{W}$ experiments, in which $\mathrm{COMPO}^{\mathrm{W}}$ wind-stress anomalies trigger equatorial and subsequent coastal wave propagations over a steady ocean mean-state. This set of experiments is described in section 4.2 and summarized in Table 1. Anomalies are estimated with respect to the ensemble-mean of the unperturbed $\overline{\mathrm{EXP}}$ experiments (Table 1 ).

The timeseries of $\overline{\mathrm{EXP}}^{W}$ SLA averaged in the ATL3 and CABA regions is presented in Figure 5b. Positive anomalies of $1-3 \mathrm{~cm}$ are depicted in both regions for each of the 10 ensemble simulations. In the ATL3 region, the ensemble-mean peaks at $+1.5 \mathrm{~cm}$ (red line in Figure $5 \mathrm{~b}$ ), 3.75 months after the beginning of the experiments, that is, 6 days after the WCEA zonal wind-stress anomaly peaks (gray vertical lines in Figures 5a-5c). The peak in the ensemble-mean coastal SLA off Angola (averaged in the CABA domain, $+1.4 \mathrm{~cm}$, cf. blue line in Figure $5 \mathrm{~b}$ ) occurs 4.15 months after the beginning of the experiment, that is, 
(a) WCEA $\tau_{x}$ perturbation

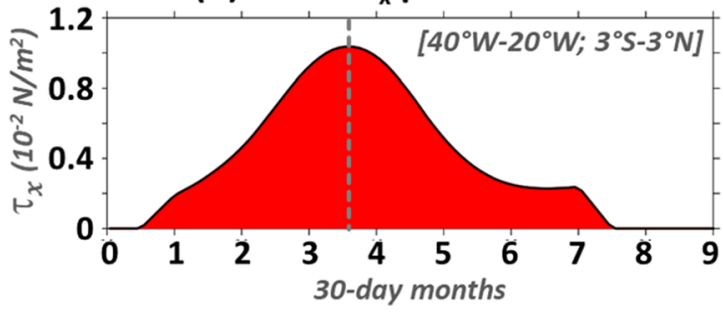

(b) $\overline{\operatorname{EXP}}^{\mathrm{W}}$ SLA in ATL3 and CABA

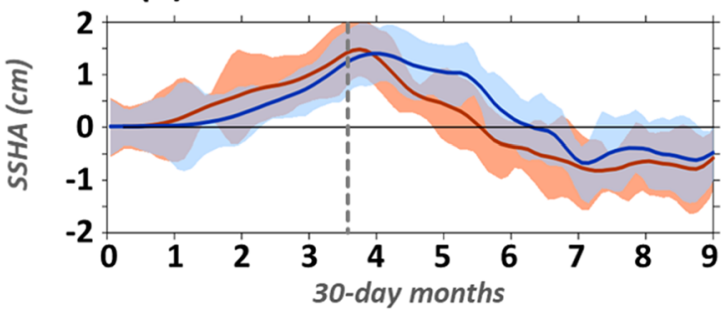

(c) $\overline{\operatorname{EXP}}^{\mathrm{W}}$ SSTA in ATL3 and CABA

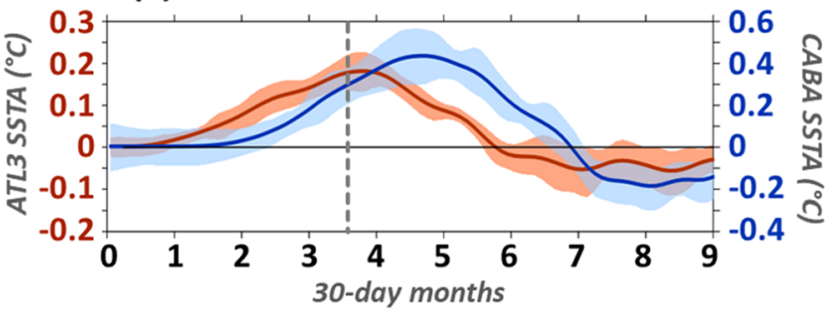

Figure 5. (a) Timeseries of model zonal wind-stress perturbations $\left(10^{-2} \mathrm{~N}\right.$. $\mathrm{m}^{2}$ ) averaged in the western-central equatorial Atlantic (WCEA domain). (b) $\overline{\mathrm{EXP}}^{\mathrm{W}}$ SLA (cm) relative to the $\overline{\mathrm{EXP}}$ ensemble-mean. Red (blue) plain line shows the ensemble-mean anomalies averaged in the ATL3 (CABA) box and the shading indicates the STD of the 10 ensemble members. (c) Same as (b) for $\overline{\operatorname{EXP}}^{\mathrm{W}}$ SST anomalies $\left({ }^{\circ} \mathrm{C}\right)$. Left (right) scale is for ATL3 (CABA) timeseries. In all the panels, the gray vertical dashed line indicates when the zonal wind-stress interannual anomalies represented in panel (a) are maximum.
12 days after the ATL3 SLA is maximum. However, due to the intrinsic model variability and to the mesoscale activity in the cold tongue region, the spread between ensemble simulations remains substantial (orange and blue shading in Figure 5b), even when outputs are averaged over large regions such as ATL3 or CABA. For instance, when analyzing each of the 10 ensemble simulations individually, peak values of ATL3 SLA range between +1.27 and $+2.47 \mathrm{~cm}$, with lags relative to WCEA zonal wind-stress maximum varying between -3 and +21 days. The delay between equatorial and coastal SLA fluctuations is thus estimated using a more robust statistical method, than the rough estimation of the delay between ensemble-mean maxima. It is based on a maximum lagged-correlation analysis that takes into account the 10 ensemble members separately. We compute the minimum and maximum lags for the 10 ensemble members, the STD of the lags, and the average of the lags. Results are displayed on Figure 6. Lags between CABA and ATL3 SLA range from +3 to +39 days, with a mean value of +14 days. In conclusion, over a stationary mean-state, remotely forced ATL3 SLA fluctuations always precede the SLA variability off the Angolan coast, in agreement with the linear dynamics and $\mathrm{CROCO}^{\mathrm{LONG}}$ results (cf. triangles in Figure 2).

Notably, the mean delay of $\sim 14$ days between eastern-equatorial and coastal variabilities (distant by $\sim 18^{\circ}$ along the Equator and $\sim 18^{\circ}$ following the coastline) is consistent with a mean propagation speed of $\sim 3.3 \mathrm{~m} . \mathrm{s}^{-1}$. This phase speed is of the order of first-mode EKW $\left(\mathrm{c}_{1}=2.5 \mathrm{~m} . \mathrm{s}^{-1}\right.$, Illig et al., 2004)-CTW ( $c_{1}=4.0 \mathrm{~m} . \mathrm{s}^{-1}$, averaged within $\left[5^{\circ} \mathrm{S}-20^{\circ} \mathrm{S}\right]$, Illig et al., 2018) propagations. However, when the lag estimate is conducted with indexes that are more confined along the wave guides (using the KATL3 box along the Equator and a $1^{\circ}$-width coastal fringe off Angola $\left.\left[10^{\circ} \mathrm{S}-20^{\circ} \mathrm{S}\right]\right)$ to better capture the signature of the trapped-waves, results give a lag of $\sim 27$ days between the equatorial and the coastal SLA fluctuations. This lag is typical of a slower propagation of $1.7 \mathrm{~m} . \mathrm{s}^{-1}$, consistent with the phase speed of a second-mode EKW $\left(\mathrm{c}_{2}=1.3 \mathrm{~m} . \mathrm{s}^{-1}\right)$-CTW $\left(c_{2}=1.9 \mathrm{~m} \cdot \mathrm{s}^{-1}\right)$, in agreement with the dominance of the second mode in the equatorial region (Illig et al., 2004) and along the coast North of $20^{\circ} \mathrm{S}$ (Bachèlery et al., 2020). Results further indicate that ATL3 SLA lags KATL3 SLA variability by 16 days (cf. gray triangle in Figure 2), which suggests that the ATL3 domain also captures some of the off-equatorial signature of reflected westward Rossby wave propagations. Nevertheless, in the $\overline{\mathrm{EXP}}^{W}$ idealized model experiment, the lag between equatorial and coastal SLA fluctuations remains positive (ATL3 leading), which rules-out the role of a distinct modal contribution of the waves between the equatorial region (Mode 2) and the coastal area (Mode 1 in the South) to explain the observed time-sequence of the SSTA events (cf. Figure 1b).

The $\overline{\mathrm{EXP}}^{W}$ SSTA response and its timing are shown in Figures $5 \mathrm{c}$ and 6. Results first reveal that the dispersion between ensemble-members for the ATL3 and CABA SSTA timeseries is weaker, in terms of magnitude and time-sequence (cf. shadings in Figures $5 \mathrm{c}$ and 6), compared to the dispersion of SLA. In the cold tongue region, the surface warming is relatively weak, ranging from $0.15^{\circ} \mathrm{C}$ to $0.24^{\circ} \mathrm{C}$. The ensemble-mean ATL3 warming does not reach $0.2^{\circ} \mathrm{C}$ (cf. red line in Figure 5c) and occurs 12 days after the maximum in WCEA zonal wind-stress anomaly, that is, 6 days after the ATL3 SLA peaks. It is important here to recall that the turbulent heat fluxes in $\overline{\mathrm{EXP}}^{W}$ experiments are estimated based on bulk formulae using mean DFS 10-m wind amplitude, 2-m temperature, and humidity (cf. section 4.2). This tends to create a Newtonian cooling that damps the magnitude of the event in the surface layer. Accordingly, the warming is substantially stronger in the subsurface (Figure 7a). It exceeds $1^{\circ} \mathrm{C}$ where the maximum vertical temperature gradients are located ( $\sim 50 \mathrm{~m}$ depth). In addition to the unrealistic heat fluxes formulation, the mean 


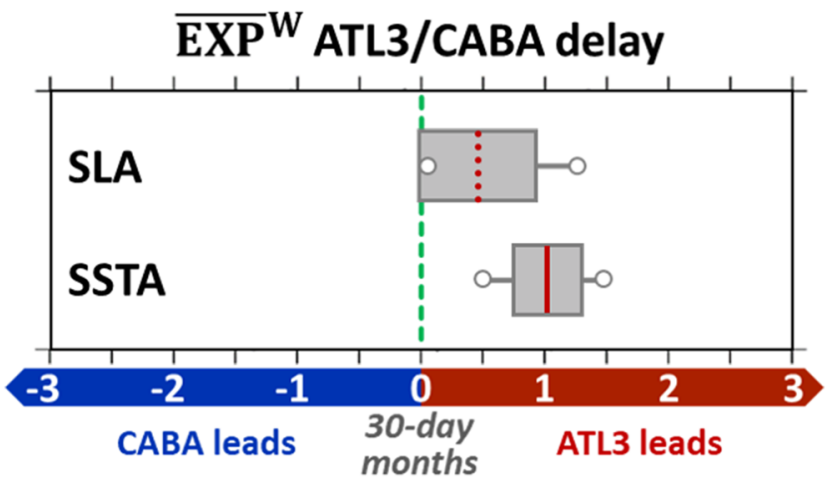

Figure 6. Box and whisker plot representing the delay between the occurrence of positive SL and SST anomalies in the eastern-equatorial Atlantic (ATL3 box) and anomalies in the coastal Angola Benguela Area (CABA box) for the $\overline{\mathrm{EXP}}^{\mathrm{W}}$ experiments, based on maximum lagged-correlation analyses. Red vertical line is the mean of the 10 ensemble member lag estimates. The gray box shows the dispersion of the 10 ensemble members $( \pm 1$ STD $)$ and whiskers denote the minimum and maximum estimates. Positive lags indicate that ATL3 fluctuations lead CABA variability, in agreement with an equatorial/ coastal wave propagation sequence. vertical stratification imposed in $\overline{\mathrm{EXP}}$ series of experiments is also not favorable for the warming to reach the surface layer. Although the vertical temperature gradients are strong $\left(>0.22^{\circ} \mathrm{C} / \mathrm{m}\right)$, the equatorial upwelling remains weak $\left(<0.4 \mathrm{~m} \cdot \mathrm{day}^{-1}\right.$ at $54 \mathrm{~m}$ depth$)$. The thermocline is relatively deep: $48 \mathrm{~m}$ at rest and $56 \mathrm{~m}$ during the passage of the downwelling EKW (cf. gray-shaded ribbon in Figure 7a). As a result, the temperature anomalies barely penetrate the mixed layer which lies above $40 \mathrm{~m}$-depth (cf. dashed line in Figure 7a). Notably, the warming in the subsurface is quasi-concomitant with the surface fluctuations, occurring just 3 days before the surface temperature peaks. Off Angola, the coastal temperature anomalies (averaged over CABA) are more homogeneous above the thermocline (cf. Figure $7 \mathrm{~b}$ ). The subsurface warming reaches $0.6^{\circ} \mathrm{C}$, while the SSTA exceeds $0.4^{\circ} \mathrm{C}$ (blue line in Figure $5 \mathrm{c}$ ). The coastal thermocline is shallower $(\sim 30-40 \mathrm{~m})$ than in the eastern-equatorial sector, but it remains $10-15 \mathrm{~m}$ deeper than the base of the mixed layer. The coastal upwelling $(<0.14 \mathrm{~m}$. day $^{-1}$ at $30 \mathrm{~m}$ depth $)$ and the vertical thermal gradients $\left(<0.12^{\circ} \mathrm{C} / \mathrm{m}\right)$ are relatively weak, compared to the ones in the eastern-equatorial region. This implies that, in addition to vertical processes, the meridional advection of warm equatorial waters plays a significant role in the coastal warming, as suggested by Rouault (2012). As a consequence, subsurface and surface temperature anomalies peak at the same time (cf. Figure $7 \mathrm{~b}$ ). Results show that, on average over the 10 ensemble-members, the coastal temperature off Angola peaks $~ 33$ days after the maximum in SSTA in the cold tongue region (cf. Figure 6).

In conclusion, when wind-stress perturbations are applied in the western-central Atlantic over a steady mean-state, the SSTA fluctuations at the coast follow the ones in the eastern-equatorial sector by $\sim 1$ month, in line with what is expected from the linear wave dynamics. This implies that neither distinct modal wave contributions nor the differences in thermocline depths between the two regions explain the observed time-sequence between ATL3 and CABA SSTA timeseries. In the following section, we examine if the seasonal modulation of the ocean mean-state can impact the sequence of the waves or the ocean thermal response of the surface layer.
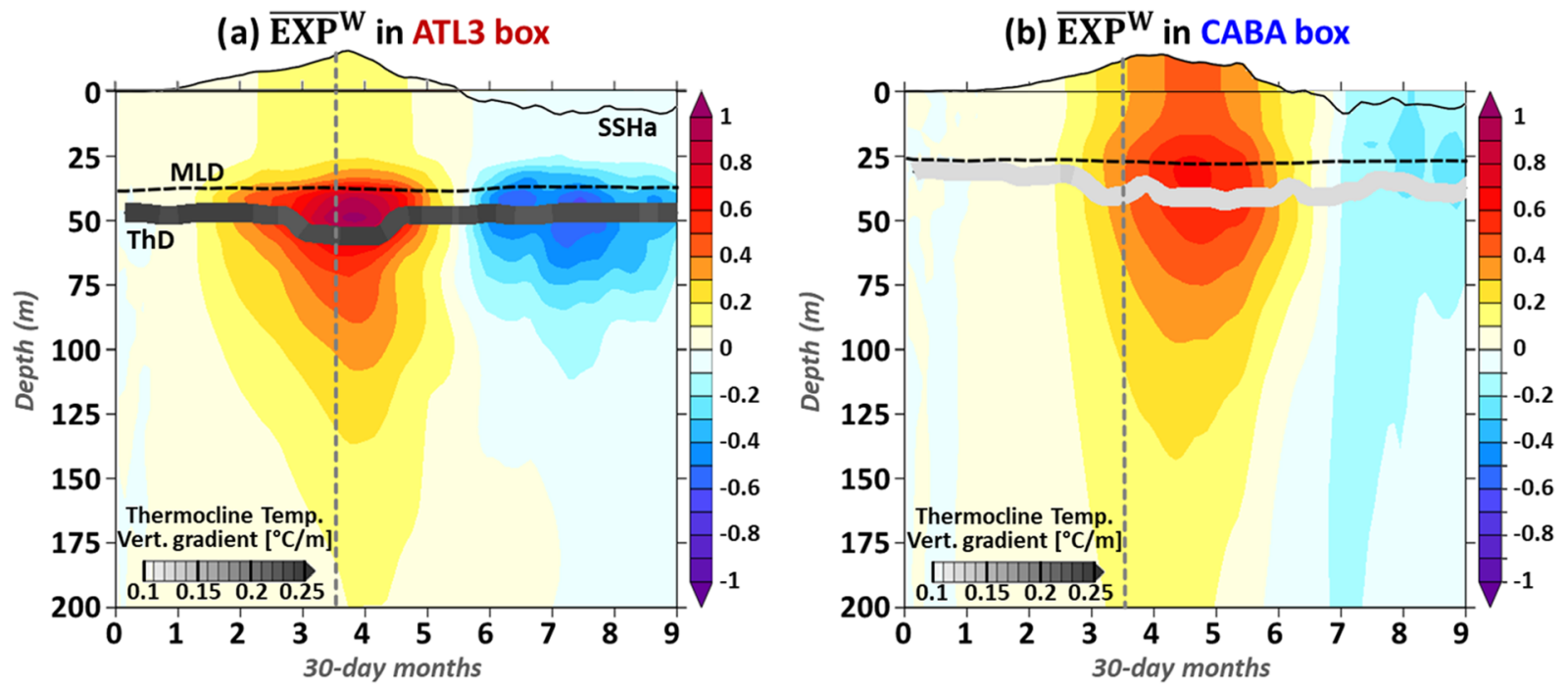

Figure 7. (a) $\overline{\mathrm{EXP}}^{\mathrm{W}}$ anomalies averaged in (a) ATL3 and (b) CABA boxes. Color shading represents $\overline{\mathrm{EXP}}^{\mathrm{W}}$ ensemble-mean temperature anomalies $\left({ }^{\circ} \mathrm{C}\right)$ relative the $\overline{\text { EXP }}$ ensemble-mean as a function of depth $(\mathrm{m})$ and time. Overstated variations of the free surface denote the evolution of the ensemble-mean SLA. The black dashed line shows the $\overline{\mathrm{EXP}}^{\mathrm{W}}$ ensemble-mean depth of the mixed layer HBL, computed by the KPP model. The polytube indicates the depth of the thermocline (where thermal stratification is maximum) and its gray shading quantifies the associated vertical temperature gradients. The gray vertical dashed line indicates when the zonal wind-stress interannual anomalies represented in Figure 5a are maximum. 
(a) $\widetilde{\operatorname{EXP}}^{\mathrm{W}}$ D20A in ATL3 (m)
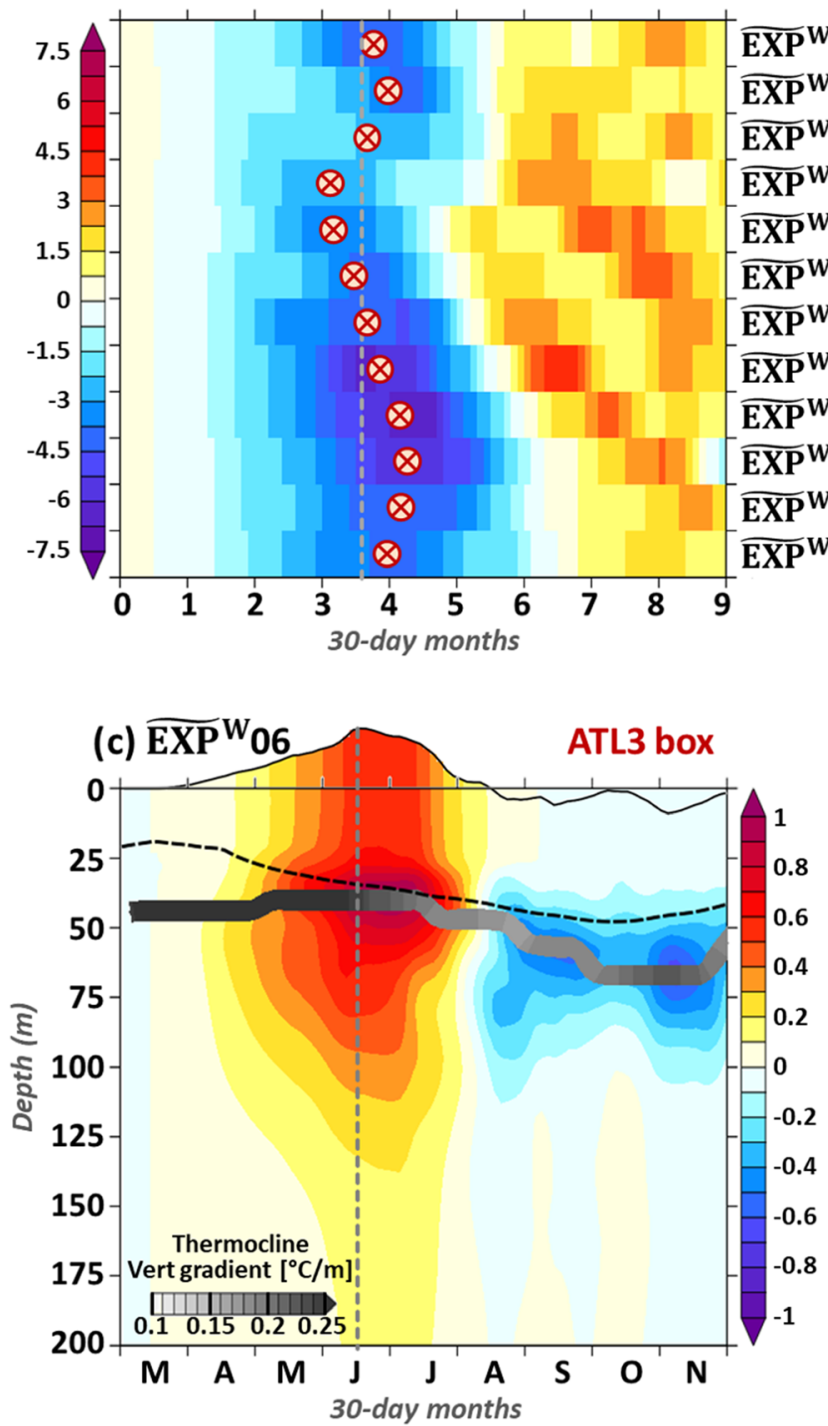

(b) $\widetilde{\operatorname{EXP}}^{\mathrm{W}}$ SSTA in ATL3 $\left(^{\circ} \mathrm{C}\right)$
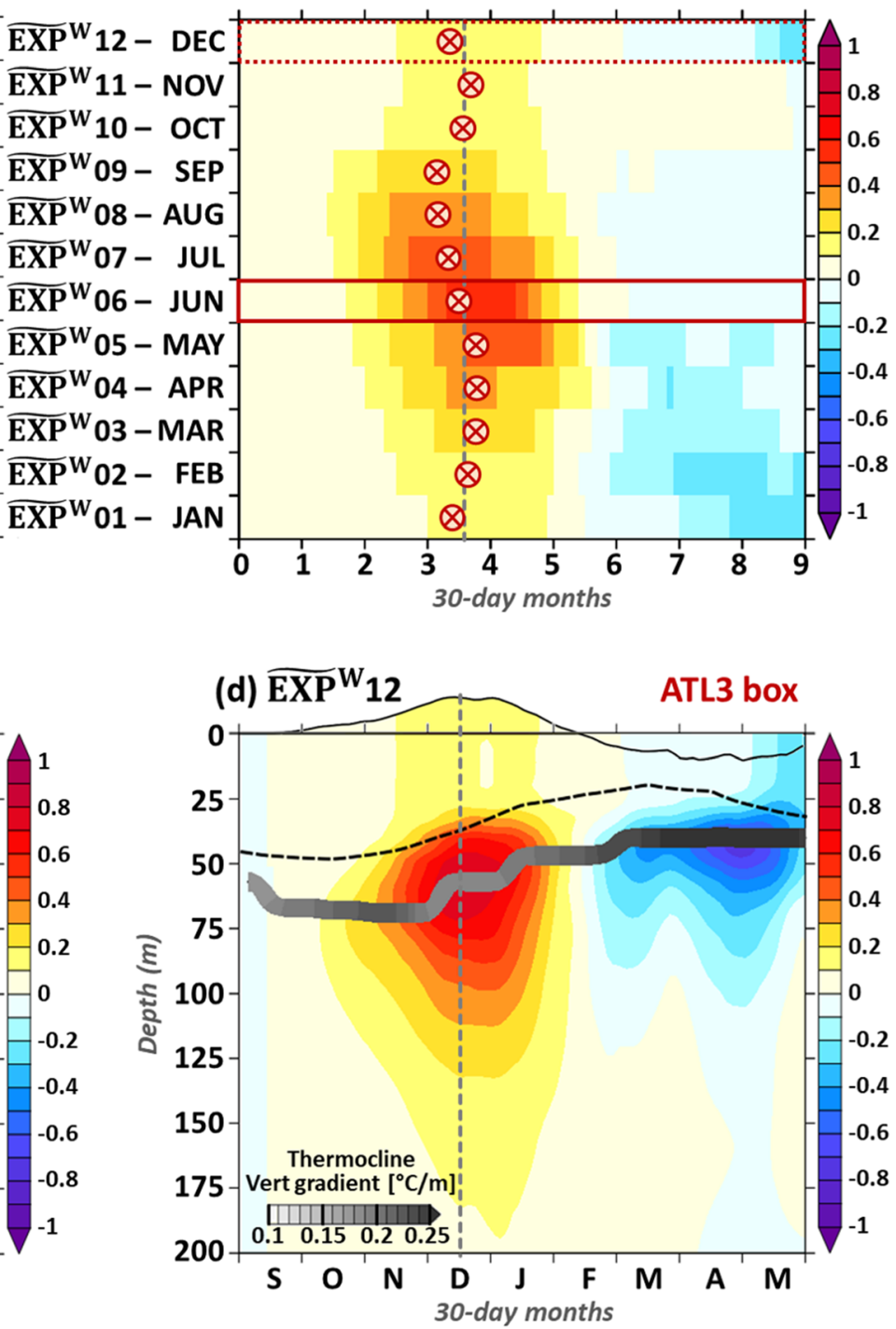

Figure 8. $\widetilde{\mathrm{EXP}}^{\mathrm{W}}$ ensemble-mean thermocline depth anomalies $(\mathrm{a} ; \mathrm{m})$ and SSTA $\left(\mathrm{b} ;{ }^{\circ} \mathrm{C}\right)$ averaged in the ATL3 box as a function of time (x-axis, in months) and for the 12 experiments (y-axis). The depth of the isotherm $20^{\circ} \mathrm{C}$ (D20) is used as a proxy for the eastern equatorial thermocline depth. Circled-crosses position the lag at which the correlation between WCEA zonal wind-stress perturbations and $\widetilde{\mathrm{EXP}^{\mathrm{W}}}$ ATL3 anomalies is maximum. It is arbitrarily positioned with respect to the maximum WCEA zonal wind-stress perturbations (Figure 5a) indicated by the gray vertical dashed line. In panel (b), the plain (dashed) line empty rectangle emphasizes the experiment in which the SSTA events are maximum (minimum). (c, d) Same as Figure 7a for $\widetilde{\mathrm{EXP}}^{\mathrm{W}} 06$ and $\widetilde{\mathrm{EXP}}^{\mathrm{W}} 12$, respectively.

\subsection{Model Output Analysis: Warm Events in a Seasonally Varying Ocean Mean-State}

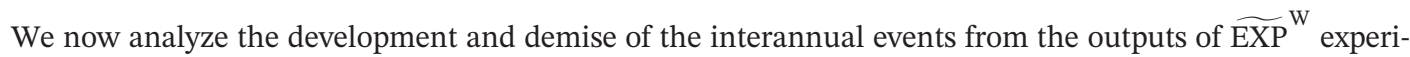
ments, in which the ocean state varies seasonally and the remote COMPO ${ }^{\mathrm{W}}$ wind-stress forcing is applied successively at each month of the year (cf. section 4.2 and Table 2). Anomalies are estimated with respect to the ensemble-mean of the unperturbed $\widetilde{\mathrm{EXP}}$ experiments (cf. Table 2).

Figure 8a presents the $\widetilde{\mathrm{EXP}}{ }^{\mathrm{W}}$ ensemble-mean dynamical response in the cold tongue region over a 9-month period (x-axis) to identical WCEA wind-stress anomalies prescribed at different seasons (y-axis). We analyze the anomalies of the depth of the $20^{\circ} \mathrm{C}$ isotherm (D20A, as a proxy for the equatorial thermocline depth) rather than the SLA fluctuations as the latter may also capture the nonlinear seasonal effects of the thermal expansion. We remind the reader that in a 1.5-layer system, SLA fluctuations are inversely mirrored in the 
thermocline depth. Noteworthy, in a multimode system, higher-order baroclinic modes weigh more on the subsurface density displacements than on the SLA (cf. Dewitte (2000) and Clarke and Van Gorder (1986) for EKW and CTW, respectively). This results in propagations that are slower when detected from thermocline variations than from SLA fluctuations. Similar to Figures 5 and 7, the gray vertical dashed line in Figure 8a indicates when the WCEA zonal wind-stress anomaly is maximum, with the corresponding month specified on the $y$-axis label. Maximum downwelling anomalies (D20A $<-5 \mathrm{~m}$ ) are found when the forcing is applied in March-April-May and November-December seasons which coincide with the seasonal maxima of the second mode wind-stress projection coefficient (see Figure A2 in Illig et al., 2004). The response for a forcing applied in April $\left(\widetilde{\mathrm{EXP}^{\mathrm{W}}}\right.$ 04) is 2.5 times stronger than in September $\left(\widetilde{\mathrm{EXP}}^{\mathrm{W}}\right.$ 09). Results also highlight a substantial seasonal modulation of the delay between the WCEA zonal wind-stress perturbations and the eastern-equatorial D20A variability, depending on the month at which the forcing is applied. The delay is estimated based on lag-correlation analyses and represented with circled-crosses in Figure 8a. When the forcing peaks in August-September, D20A peak slightly before the WCEA zonal wind-stress maximum, suggesting a substantial contribution of the fast first EKW mode. Larger lags occur when the forcing is applied during the months of February-March-April and November, in phase with the months during which the forcing of the slower third baroclinic mode is stronger (Illig et al., 2004). During the remainder of the year, the delay between forcing and D20A is consistent with the phase-speed of the dominant second-mode EKWs.

Notably, the associated thermal response shows an even more marked seasonal modulation of the eastern-equatorial SSTA (Figure 8b). The strongest surface warming (ATL3 SSTA $>0.5^{\circ} \mathrm{C}$ ) occurs when the remote forcing is applied in the MJJ season, in agreement with the seasonal phasing of the Atlantic Niño events (Illig \& Dewitte, 2006; Keenlyside \& Latif, 2007) and with the seasonal modulation of the eastern-equatorial interannual variability (cf. Figure S2f). $\widetilde{\mathrm{EXP}}^{\mathrm{W}} 06$ experiment (plain dark-red rectangle in Figure $8 \mathrm{~b})$ experiences the largest SSTA $\left(>0.6^{\circ} \mathrm{C}, 9\right.$ days after the maximum in WCEA zonal wind-stress anomaly) in the cold tongue region. In subsurface, $\widetilde{\mathrm{EXP}}^{\mathrm{W}} 06$ interannual warming (Figure 8c) reaches $1^{\circ} \mathrm{C}$ at $40 \mathrm{~m}$-depth, almost in phase with the surface peak (6 days after). The largest subsurface temperature anomalies (positive and negative) coincide well with the position of the thermocline (gray-shaded ribbon in Figure 8c). Due to the seasonal intensification of the trade winds in MJJ, the equatorial upwelling is strong ( $>0.6$ m.day ${ }^{-1}$ at $45-\mathrm{m}$ depth, that is, 1.5 times larger than the annual mean at this depth) and the thermocline is shallowest $(\sim 40 \mathrm{~m})$. This allows an efficient penetration of the subsurface temperature anomalies in the adjoining mixed-layer. During the secondary upwelling season (Okumura \& Xie, 2004), in NovemberDecember-January (NDJ), the subsurface temperature anomalies remain strong $\left(>0.8^{\circ} \mathrm{C}\right.$ at $55 \mathrm{~m}$-depth for $\widetilde{\mathrm{EXP}}{ }^{\mathrm{w}} 12$, Figure 8d). The ratio between MJJ and NDJ maximum subsurface warming does not exceed 1.2. However, during NDJ, the equatorial upwelling is weaker and deeper ( $0.43 \mathrm{~m}$.day ${ }^{-1}$ at $\left.60 \mathrm{~m} \mathrm{depth}\right)$. The water column is less stratified $\left(\sim 0.15^{\circ} \mathrm{C} / \mathrm{m}\right)$, the thermocline is deep $(\sim 60-65 \mathrm{~m})$ and distant from the base of the mixed layer (cf. Figure 8d). As a result, the surface layer experiences a substantially weaker thermal response $\left(<0.15^{\circ} \mathrm{C}\right)$, and the ratio between MJJ and NDJ maximum SSTA is $\sim 4$ (cf. Figure $\left.8 \mathrm{~b}\right)$. Results also highlight a seasonal modulation of the delay between WCEA zonal wind-stress perturbations and the eastern-equatorial SSTA fluctuations (red circled-crossed in Figure 8b), in phase with the ocean dynamical response to the anomalous wind-stress forcing (Figure 8a). Note that the decrease of the delay between the WCEA anomalous forcing and the ATL3 SSTA response in May-to-September could also be interpreted as a phasing of the surface variability to the maximum upwelling season in June.

Off Angola, $\widetilde{\mathrm{EXP}}^{\mathrm{W}}$ dynamical response is examined through the analysis of the fluctuations of the depth of the $15^{\circ} \mathrm{C}$ isotherm (D15A, as a proxy for the coastal thermocline depth) averaged within CABA for the ensemble-mean (Figure 9a). Maximum downwelling anomalies are depicted in August-September $(\mathrm{D} 15 \mathrm{~A}<-7 \mathrm{~m})$, but the seasonal modulation of the D15A magnitude remains weak $(<20 \%)$ compared to the averaged D15A minimum of the $12 \widetilde{\mathrm{EXP}^{\mathrm{W}}}$ experiments. On average over the $12 \widetilde{\mathrm{EXP}} \mathrm{W}$ experiments, the CABA D15A variability lags the ATL3 D20A fluctuations (Figure 8a) by 25 days. Note that, the delay estimated using SLA is shorter (14 days) because of the different distribution of energy (modal contribution) on the thermocline displacements vs. SLA (Clarke \& Van Gorder, 1986; Dewitte, 2000). Figure 9a also highlights a modulation of 15 days between the WCEA wind-stress perturbations and the deepening of the coastal thermocline, depending on the month at which the forcing is applied. We report a minimum (maximum) of 
(a) $\widetilde{\operatorname{EXP}}^{\mathrm{W}}$ D15A in CABA $(\mathrm{m})$
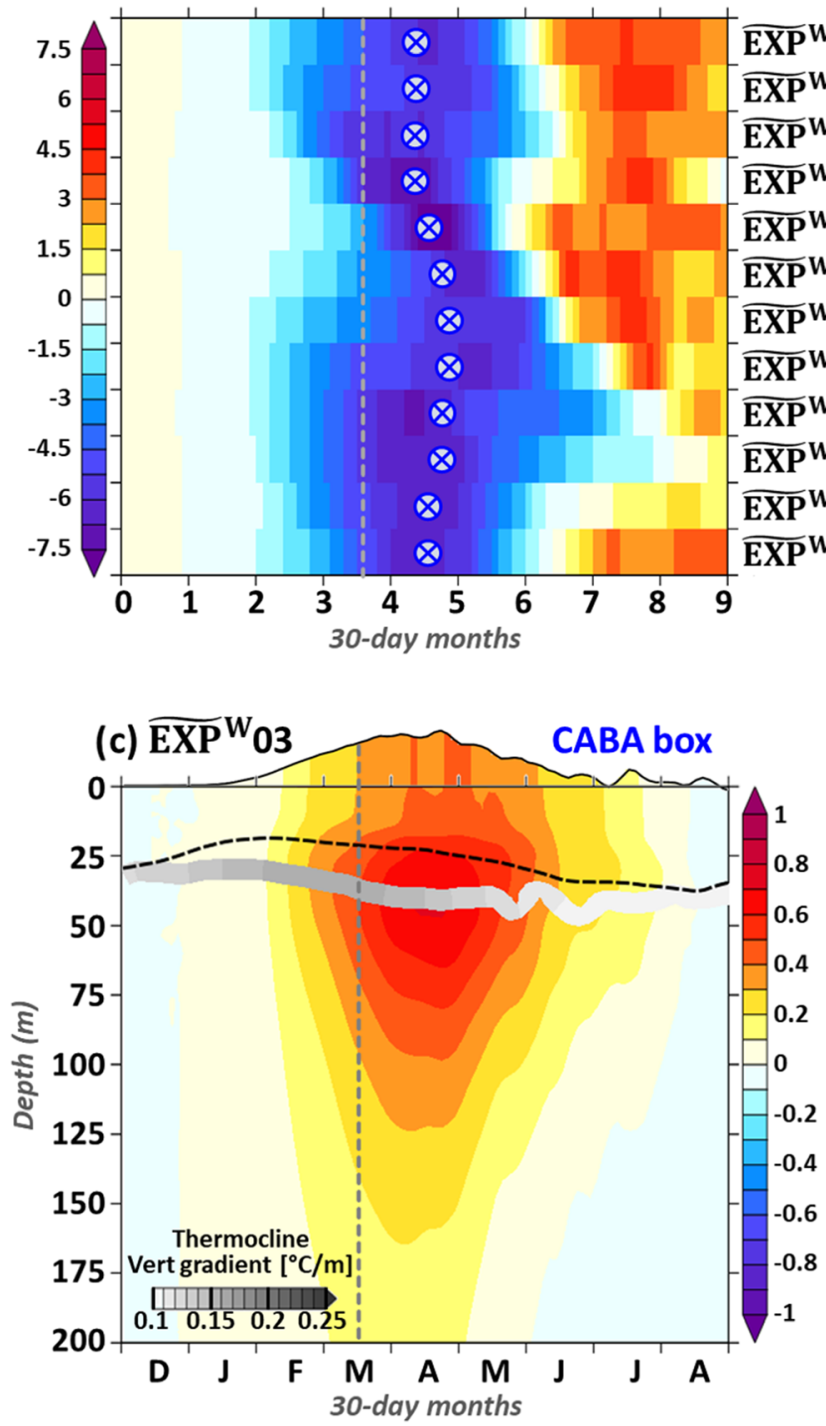

(b) $\widetilde{\operatorname{EXP}}^{\mathrm{W}}$ SSTA in CABA $\left({ }^{\circ} \mathrm{C}\right)$
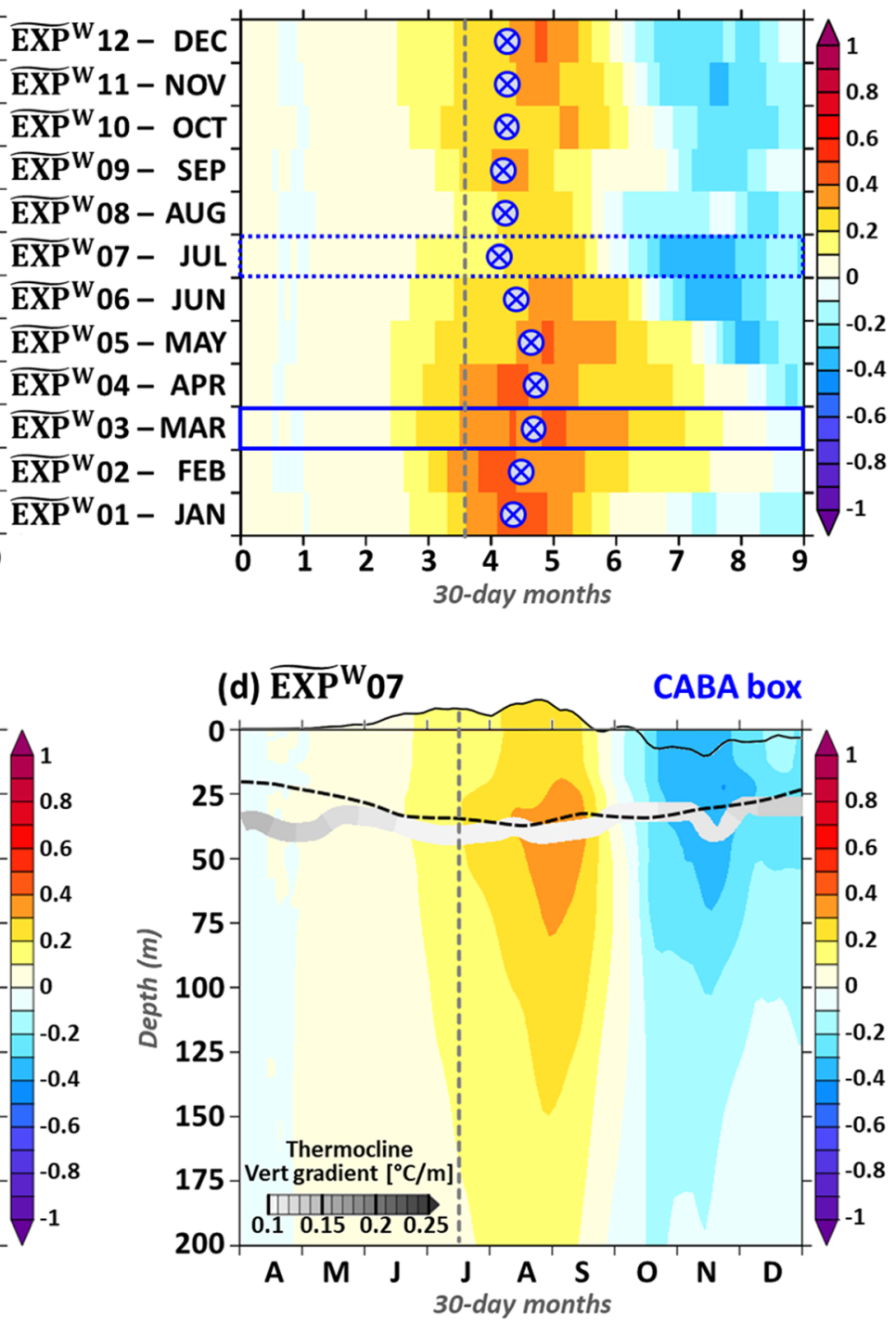

Figure 9. Coastal interannual fluctuations off Angola for $\widetilde{\mathrm{EXP}}^{\mathrm{W}}$ ensemble-mean. Same as Figure 8 for the CABA region. In panel (a), the depth of the isotherm $15^{\circ} \mathrm{C}$ (D15) is used as a proxy for the coastal thermocline depth. Panels (c) and (d), are the same as Figure $7 \mathrm{~b}$ for $\widetilde{\operatorname{EXP}}^{\mathrm{W}} 03$ and $\widetilde{\mathrm{EXP}}^{\mathrm{W}} 07$, respectively.

15 days (30 days) for $\widetilde{\mathrm{EXP}}^{\mathrm{W}}$ 09-to-12 $\widetilde{\mathrm{EXP}}^{\mathrm{W}}$ 05-06). Interestingly, this seasonal modulation is similar to the one reported in the equatorial region but shifted forward in time by 1 month. Also, unlike the equatorial region, the lags remain constant during the last trimester of the year, suggesting that the equatorially forced third-mode CTW do not shape the dynamical response in the CABA region. The modulation of the D15A fluctuations results in a delay between ATL3 and CABA thermocline deepening ranging from 12 $\left(\widetilde{\mathrm{EXP}} \mathrm{W}^{11}\right)$ to $\sim 40$ days $\left(\widetilde{\mathrm{EXP}} \mathrm{W}^{08}\right)$, with the ATL3 variability leading. To explain this seasonal modulation, it would require to decompose the equatorial and coastal variabilities into EKW and CTW modal contributions as in Bachèlery et al. (2020), which is beyond the scope of the present study. However, regardless of the month at which the WCEA forcing is applied, coastal downwelling anomalies (Figure 9a) always lag the eastern-equatorial thermocline fluctuations (Figure 8a), consistently with the time-sequence expected from remotely forced equatorial/coastal wave propagations.

In the CABA, the maximum surface warming occurs when the remote forcing is applied during the February-March-April (FMA) season (Figure 9b), in agreement with the seasonality of Benguela Niño 
$\widetilde{\operatorname{EXP}}^{\mathrm{W}}$ ATL3/CABA delay

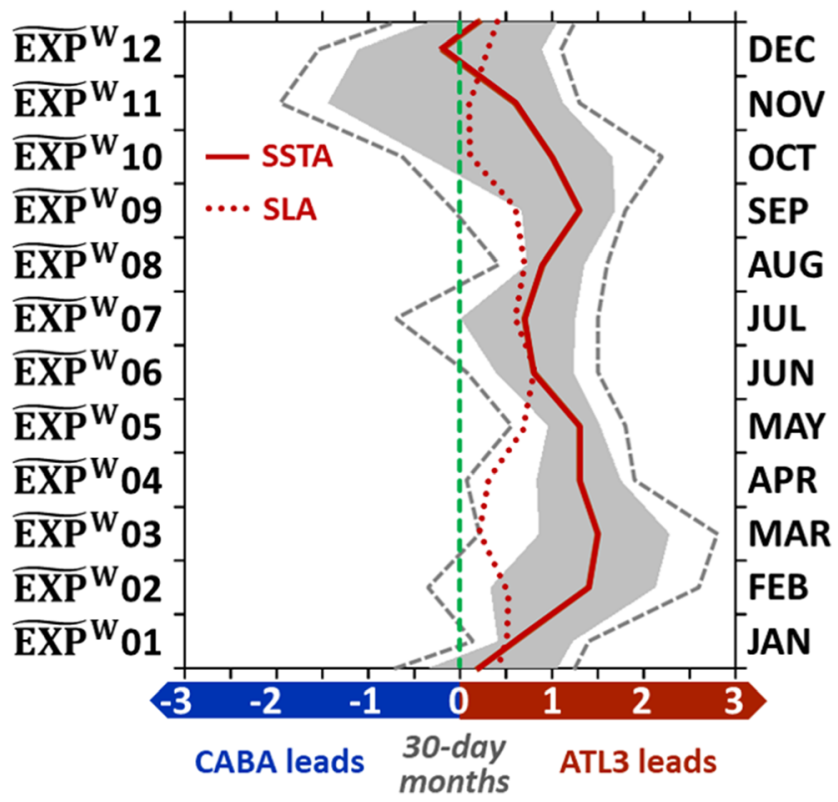

Figure 10. Delay between $\widetilde{\mathrm{EXP}}^{\mathrm{W}}$ ATL3 and CABA surface anomalous fluctuations for the $12 \widetilde{\mathrm{EXP}}^{\mathrm{W}}$ experiments (y-axis), based on maximum lagged-correlation analyses. Plain red line (gray shading) is the mean (dispersion, \pm 1 STD) of the 10 ensemble member SSTA lag estimates. The gray dashed lines show the minimum and maximum estimates. Dotted red line is the mean of the 10 ensemble member SLA lag estimates. Positive lags indicate that ATL3 fluctuations lead CABA variability. events (Florenchie et al., 2004; Imbol Koungue et al., 2019; Lübbecke et al., 2010). In $\widetilde{\mathrm{EXP}}^{\mathrm{W}} 03$ (plain blue rectangle in Figure 9b), the maximum SSTA averaged in the CABA box is $0.42^{\circ} \mathrm{C}$. The subsurface warming is in phase with the SSTA and reaches $0.8^{\circ} \mathrm{C}$ in April at the depth where the vertical thermal gradients are maximum (at 42 m-depth, Figure 9c). When the WCEA wind-stress anomaly is prescribed in June, July, or August, the warming in the surface and subsurface layers is very weak. For instance, in $\widetilde{\mathrm{EXP}}^{\mathrm{W}}$ 07 (Figure 9d), the CABA SSTA does not exceed $0.25^{\circ} \mathrm{C}$ in August and the maximum subsurface temperature anomaly is $0.38^{\circ} \mathrm{C}$ (at $38 \mathrm{~m}$-depth), 15 days after the peak in SSTA. Unlike in the equatorial case (Figure 8c), the forcing season which favors the strongest warming off Angola (FMA, cf. Figure 9c) occurs when the coastal thermocline is weakly stratified and when it is the most distant to the base of the mixed layer. It is not phased with the maximum coastal upwelling season $\left(>0.2\right.$ m.day $^{-1}$ at $30 \mathrm{~m}$ depth in MJJ with, i.e. twice as large as the annual mean at this depth), highlighting the importance of the meridional advection of warm equatorward water. The strongest warming indeed corresponds to the period during which the ABF is at its southernmost position (Lübbecke et al., 2010), prone to strong coastal meridional temperature gradients. The seasonal modulation of the coastal ocean response is however weaker than in the cold tongue region, with a ratio between CABA strongest and weakest temperature of 1.7 (2) in the surface (subsurface) layer. This indicates that the seasonal phasing of Benguela Niño events is controlled to a larger extent by the seasonality of the equatorial wave forcing. Figure $9 \mathrm{~b}$ also reveals a seasonal variability of the delay between WCEA wind-stress perturbations and CABA SSTA (circled-crosses on Figure 9b). During the April-to-August forcing season, the latter strays from the dynamical response, highlighting the importance of nonlinear and thermodynamic processes.

The delay between the SSTA fluctuations in the eastern-equatorial (ATL3)

and the coastal (CABA) sectors is presented in Figure 10 for the $\widetilde{\mathrm{EXP}} \mathrm{W}$ set of experiments. This figure is based on lag-correlation analyses of the 10 ensemble members analyzed separately, similar to Figure 6, but for each month at which $\mathrm{COMPO}^{\mathrm{W}}$ remote wind-stress forcing is applied (y-axis). Results indicate that the spread between ensemble-members is high with extreme cases in which coastal variability leads (lags) the equatorial one by $\sim 2$ (3) months. However, on average over the 10 ensemble members, the surface coastal thermal response (CABA SSTA) almost always occurs after the SSTA variability in the eastern-equatorial basin, except when the forcing is applied in December. On average over the 12 experiments, CABA SSTA variability lags ATL3 SSTA fluctuations by 28 days (Figure 10), in good agreement with $\overline{\mathrm{EXP}}^{W}$ (Figure 6). This is also the case for the SLA averaged for the $12 \widetilde{\mathrm{EXP}^{\mathrm{W}}}$ experiments: CABA SLA variability lags ATL3 SLA fluctuations by 14 days. These positive lags remain consistent with the scenario of remotely forced equatorial/coastal wave propagations. We note a substantial modulation of the delay between ATL3 and CABA SLA, depending on the month at which the wind-stress perturbations are prescribed. It is maximum during boreal springsummer, in good agreement with the delay between ATL3 and CABA dynamical response (cf. Figures 8a and 9a). The delay between ATL3 and CABA SSTA reveals a marked semi-annual modulation of the mean delay between ATL3 and CABA SSTA, highlighting two periods for which the delay is longer than the $\sim 1$ month delay of $\overline{\operatorname{EXP}}^{W}$ (cf. Figure 6): February-to-May and August-to-October. The modulation of the timing of SLA and SSTA variabilities between the eastern-equatorial and the coastal sectors shows that the characteristics of the ocean mean-state and its stratification have a substantial effect on the delay between the equatorial and the coastal variabilities, affecting both the waves propagation properties and the thermodynamic processes.

As mentioned previously, when the remote forcing is applied in December, on average over the 10 ensemble members, the SSTA in the Angola-Benguela region develops 6 days before the one the equatorial sector, 
while $\widetilde{\mathrm{EXP}}^{\mathrm{W}} 12$ CABA lags ATL3 SLA by 6 days (Figure 10). On the one hand, this result suggests that the particular ocean state in December can favor fast first-mode propagations that impact the coastal SSTA before slower propagations (higher-order modes) modulate the eastern-equatorial SST, similar to the dynamics uncovered in Illig and Bachèlery (2019). A deep equatorial thermocline also seems to lead to a slower thermodynamic response along the equator, as suggested by Lübbecke et al. (2010). On the other hand, the ocean stratification in December is not favorable to extreme SST events, neither in the cold tongue region (cf. Figures $8 \mathrm{~b}$ and $8 \mathrm{~d}$ ) nor along the coast of southwestern Africa (cf. Figure 9b). Most of the events depicted in the composite analysis indeed occur in the MJJ season which is associated with positive lags (ATL3 leads) in Figure 10. Note also that $\overline{\mathrm{EXP}}^{W} 12$ 6-day lag for SSTA is less than half of what is simulated by CROCO ${ }^{\text {LONG }}$ simulation (cf. black circle Figure 2). We therefore, continue our investigation of the processes that can explain the time sequence between the equatorial and the coastal variabilities. In the following section, we will focus on the role of the local coastal wind-stress forcing on the SSTA variability off Angola.

\subsection{Model Output Analysis: Role of Local Wind-Stress Perturbations}

As suggested by Polo et al. (2008) and Richter et al. (2010), the local atmospheric forcing in the coastal fringe off southwestern Africa can play a significant role in the interannual coastal variability. In agreement, Bachèlery et al. (2016) argued that coastal forcing can modulate the magnitude and the timing of the remote-forcing. CROCO ${ }^{\mathrm{LONG}}$ composites (section 5.1 and Figure 4) indeed revealed an anomalous surface wind-stress signal in the southeastern Atlantic associated with extreme SSTA events (cf. section 5.1). A substantial relaxation of the equatorward coastal meridional wind-stress is found 4 months before the peak in WCEA zonal wind-stress anomalies (Figure 11a), followed by an acceleration of the coastal winds. In the following, we will test if this anomalous atmospheric circulation can impact the timing between equatorial and coastal SSTA variabilities. To do so, we analyze the outputs of $\overline{\mathrm{EXP}}^{A}$ (cf. section 4.2 and Table 1) and $\widetilde{\mathrm{EXP}}^{\mathrm{A}}$ (cf. Table 2) experiments, in which interannual wind-stress anomalies impact the ocean variability off Angola $\left(\mathrm{COMPO}^{\mathrm{A}}\right)$ through coastal upwelling/circulation modulation and locally forced CTW, in addition to the remotely forced propagations.

Figure 11 presents $\overline{\mathrm{EXP}}^{A}$ outputs in which anomalies are induced over a steady ocean mean-state. Assuming some linearity, the impact of the southeastern wind-stress perturbations can be quantified by comparing $\overline{\mathrm{EXP}}^{A}$ interannual anomalies to the one of $\overline{\mathrm{EXP}}^{W}$ (Figures 5-7). In the ATL3 region, the ensemble-mean of $\overline{\mathrm{EXP}}^{A}$ anomalies (Figure 11b) is very similar to $\overline{\mathrm{EXP}}^{W}$ response (Figure 7a). In the surface (subsurface) layer, the peak in $\overline{\mathrm{EXP}}^{A}$ temperature is warmer by only $0.015^{\circ} \mathrm{C}\left(0.02^{\circ} \mathrm{C}\right)$ and concomitant (delayed by 3 days) with $\overline{\mathrm{EXP}}^{W}$ anomalies. Off the coast of Angola (Figure 11c), $\overline{\mathrm{EXP}}^{A}$ ocean response is substantially stronger than $\overline{\mathrm{EXP}}^{W}$ (cf. Figure 7b). Along the thermocline, the temperature anomalies averaged in the CABA box exceed $0.8^{\circ} \mathrm{C}$ at $33 \mathrm{~m}$ depth, $0.2^{\circ}$ more than in $\overline{\mathrm{EXP}}^{W}$ outputs. At the peak phase of the event, CABA SLA (SSTA) peaks at $+2.1 \mathrm{~cm}\left(+0.6^{\circ} \mathrm{C}\right)$, that is, $0.7 \mathrm{~cm}\left(0.15^{\circ} \mathrm{C}\right)$ larger than in $\overline{\mathrm{EXP}}^{W}$. Notably, the coastal warm event simulated under the influence of coastal wind-stress anomalies $\left(\overline{\mathrm{EXP}}^{A}\right)$ develops and reaches its maximum prior to the event simulated in $\overline{\mathrm{EXP}}^{W}$. For instance, at $30 \mathrm{~m}$-depth, $\overline{\mathrm{EXP}}^{A}$ ensemble-mean temperature anomalies exceed $0.37^{\circ} \mathrm{C}$ only 2 months after the beginning of the experiments (Figure 11c), while in $\overline{\mathrm{EXP}}^{W}$ this threshold is surpassed 1.5 months later (Figure 7b). In $\overline{\mathrm{EXP}}^{A}$, the peak in subsurface temperature is reached in phase with the change of sign in the CABA meridional wind-stress anomalies (Figure 11a), that is, 0.8 months prior to $\overline{\mathrm{EXP}}^{W}$ maximum subsurface temperature (cf. round arrow in Figure 11c). Similarly, $\overline{\mathrm{EXP}}^{A}$ ensemble-mean SSTA reaches its maximum 1.5 months before $\overline{\mathrm{EXP}}^{W}$ SSTA peaks. As a result, the delay between the warm events simulated in the eastern-equatorial Atlantic and along the coast off Angola is changed. In $\overline{\mathrm{EXP}}^{A}$, the CABA subsurface warmest temperature (Figure 11c) occurs 6 days prior to the peak in ATL3 (Figure 11b). The ensemble-mean CABA SSTA peak also precedes the maximum SSTA in the cold tongue region by 18 days. Taking into account the spread between the ensemble-members, Figure 11d highlights a change in the timing of the equatorial/coastal SSTA variabilities of $\sim 1.33$ months, compared to the simulation in which there are no interannual coastal wind-stress fluctuations $\left(\overline{\mathrm{EXP}}^{W}\right)$. In 
(a) $\overline{\operatorname{EXP}}^{A} \mathrm{CABA} \tau$ perturbation
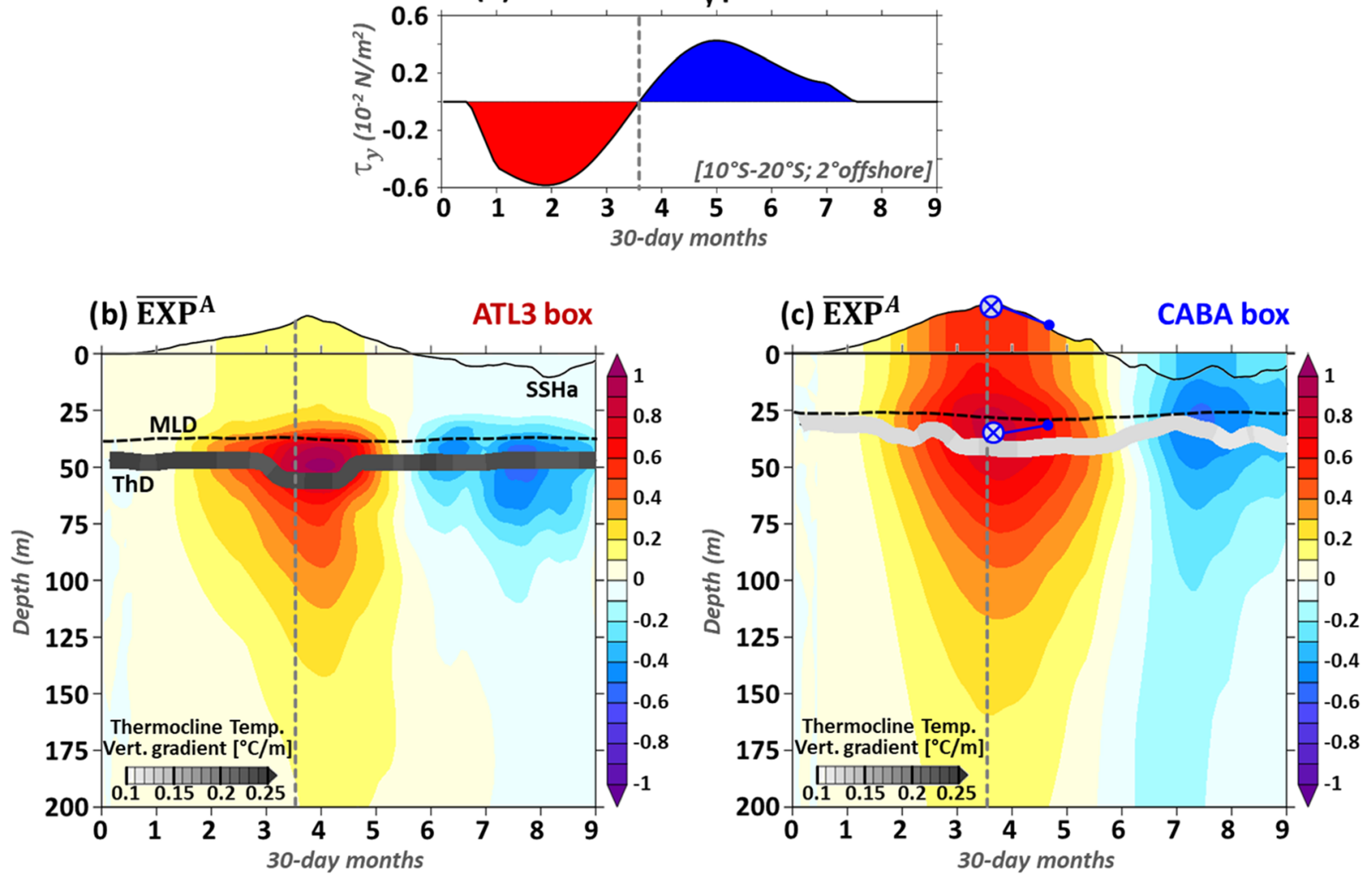

(d) $\overline{\operatorname{EXP}}^{A}$ ATL3/CABA delay

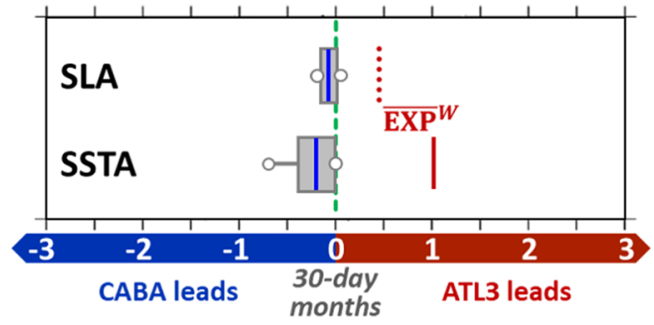

Figure 11. Interannual variability simulated in $\overline{\mathrm{EXP}}^{A}$, in which there are coastal wind-stress fluctuations off Southwest Africa (cf. Table 1). (a) Timeseries of meridional wind-stress perturbations $\left(10^{-2} \mathrm{~N} \cdot \mathrm{m}^{2}\right.$ ) averaged in the CABA box. (b) Same as Figure 7a for $\overline{\mathrm{EXP}}^{A}$. (c) Same as Figure $7 \mathrm{~b}$ for $\overline{\mathrm{EXP}}^{A}$.

Circled-crosses position the CABA maximum surface and subsurface temperature anomalies. Round arrows recall $\overline{\mathrm{EXP}}^{W}$ maximum surface and subsurface temperature anomalies from Figure 7b. (d) Same as Figure 6 for $\overline{\mathrm{EXP}}^{A}$, using plain blue line for the mean of the 10 ensemble member lag estimates. Red vertical lines recall the mean of the 10 ensemble member lag estimates of $\overline{\mathrm{EXP}}^{W}$.

$\overline{\mathrm{EXP}}^{A}$, on average over the 10 ensemble members, the CABA SSTA variability leads ATL3 SSTA fluctuations by 6 days. This delay between equatorial and coastal SSTAs is in better agreement with the observations (Figure 1) and with CROCO ${ }^{\mathrm{LONG}}$ estimations (Figures 2 and 4) than $\overline{\mathrm{EXP}}^{W}$ (cf. Figure 6) or $\widetilde{\mathrm{EXP}}^{\mathrm{W}}$ (cf. Figure 10) results. This confirms that coastal wind-stress perturbations are instrumental in controlling the observed delay between eastern-equatorial and coastal SSTA interannual variabilities.

Notably, wind-stress anomalies along the southwestern African coasts also modulate the timing of the coastal SLA fluctuations. On top of the downwelling remotely forced CTW, southerly (northerly) coastal wind anomalies before (after) the peak in WCEA zonal wind-stress anomalies (Figure 11a) trigger a decrease (increase) of the coastal upwelling associated with a deepening (shoaling) of the thermocline and a rise (depression) of the SL. As a result, $\overline{\mathrm{EXP}}^{A}$ ensemble-mean SLA timeseries averaged in the 
(a) $\widetilde{\operatorname{EXP}}^{A}$ SSTA in CABA $\left({ }^{\circ} \mathrm{C}\right)$

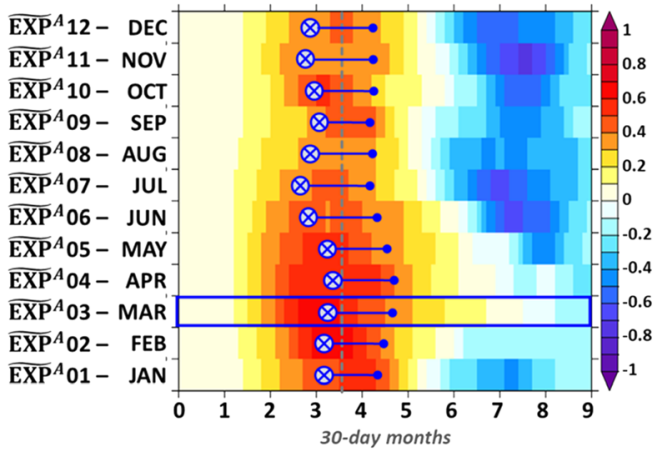

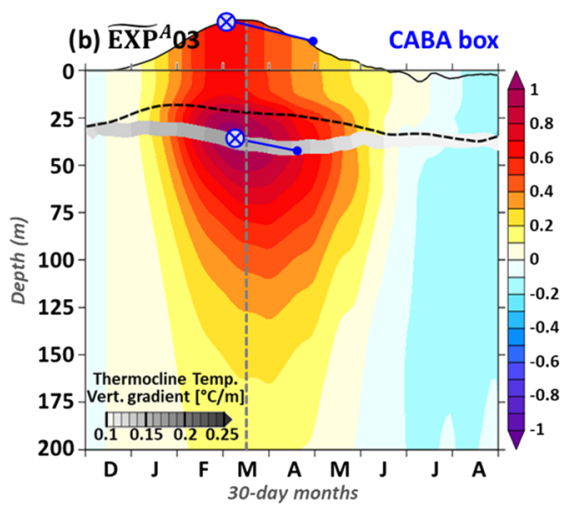

(c) ATL3/CABA delay

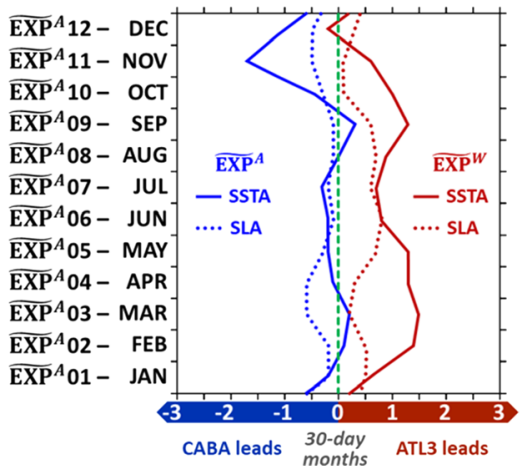

Figure 12. Interannual fluctuations for the set of experiments $\widetilde{\mathrm{EXP}}^{A}$ in which there are coastal wind stress perturbations off southwestern Africa (cf. Table 2). (a, b) Same as Figures $9 \mathrm{~b}$ and $9 \mathrm{c}$ for $\widetilde{\mathrm{EXP}}^{A}$. In panel (a), round arrows recall the lag between WCEA wind-stress perturbations and $\widetilde{\mathrm{EXP}}^{W}$ CABA SSTA (Figure $9 \mathrm{~b}$ ), while in panel (b) they recall $\widetilde{\mathrm{EXP}}^{W}$ maximum surface and subsurface temperature anomalies (Figure 9c). (c) Blue plain (dotted) line is the ensemble mean delay between ATL3 and CABA SSTA (SLA) for the $12 \widetilde{\mathrm{EXP}}^{\mathrm{A}}$ experiments, based on maximum lagged-correlation analyses. Red lines recall the ensemble-mean lag estimates of $\widetilde{\operatorname{EXP}^{\mathrm{W}}}$ (Figure 10). Positive lags indicate that ATL3 fluctuations lead CABA variability.

CABA region (Figure 11c) reaches its maximum 2 weeks before the peak in $\overline{\mathrm{EXP}}^{W}$ CABA SLA (Figure 7b), that is, 3 days before ATL3 SLA (Figure 11b). The lag-correlation analysis of $\overline{\mathrm{EXP}}^{A} 10$ ensemble-members separately highlights a backward shift larger than 2 weeks in the sequence of variability between CABA and ATL3 SLA compared to $\overline{\mathrm{EXP}}^{W}$ (Figure 11d), CABA SLA peaking on average 6 days before the peak in the cold tongue SLA. We note that composites of CROCO ${ }^{\text {LONG }}$ CABA SLA (Figure 4a) also revealed coastal SLA fluctuations leading eastern equatorial SLA variability. As reported in section 5.1, this sequence is however not in agreement with either the lag-correlation analysis between CROCO $^{\text {LONG }}$ ATL3 and CABA SLA timeseries presented in Figure 2 (cf. black triangle) or the results of Bachèlery et al. (2020). This will be discussed in section 6.

Similar to $\overline{\mathrm{EXP}}^{A}$ results, when remote and local anomalies are triggered over a seasonally varying mean-state $\left(\widetilde{\mathrm{EXP}}^{\mathrm{A}}\right)$, eastern-equatorial warm events share the same characteristics (magnitude and timing; not shown) as the ones of $\widetilde{\mathrm{EXP}^{\mathrm{W}}}$ (Figure 8). In the coastal fringe off Angola, compared to $\widetilde{\mathrm{EXP}}^{\mathrm{W}}$ (Figures $9 \mathrm{~b}$ and $9 \mathrm{c}$ ), $\widetilde{\mathrm{EXP}}^{\mathrm{A}}$ temperature response is also stronger by $\sim 25 \%$ on average over the 12 experiments (Figures $12 \mathrm{a}$ and $12 \mathrm{~b}$ ), both in surface and subsurface. The CABA SSTA variability is also shifted backward in time. For instance, during the season that favors the strongest surface warming off Angola $\left(\widetilde{\mathrm{EXP}}^{\mathrm{A}} 03\right)$, the peak in subsurface temperature $\left(1.05^{\circ} \mathrm{C}\right.$, Figure $\left.12 \mathrm{~b}\right)$ occurs 1.2 months prior to the peak in $\widetilde{\operatorname{EXP}^{2}} 03\left(0.71^{\circ} \mathrm{C}\right.$, Figure $\left.9 \mathrm{c}\right)$. On average over the 12 experiments, the lag between WCEA wind-stress perturbations and $\widetilde{\mathrm{EXP}}^{\mathrm{A}} \mathrm{CABA}$ SSTA fluctuations is shifted backward in time by 1.3 months compared to $\widetilde{\mathrm{EXP}}^{\mathrm{W}}$ (Figure 12a), with shifts ranging from -1 months $\left(\widetilde{\mathrm{EXP}}^{\mathrm{A}} 09\right)$ to -1.6 months $\left(\widetilde{\mathrm{EXP}}^{\mathrm{A}} 06\right)$. As a result, the delay between ATL3 and CABA SSTA fluctuations is significantly modified when coastal wind-stress fluctuations are switched on. On average over the 12 experiments, the maximum in ensemble-mean SSTA off Angola precedes the eastern-equatorial SSTA peak by 10 days (Figure 12a). Figure 12c portrays a marked seasonal modulation of the lag between $\widetilde{\mathrm{EXP}}^{\mathrm{A}}$ ATL3 and CABA SSTA and SLA similar to $\widetilde{\mathrm{EXP}}^{\mathrm{W}}$ results (cf. section 5.3). Results show that coastal wind-stress perturbations trigger a backward shift of the timing between ATL3 and CABA SSTA variability of 1.25 months. As a result, the delay between $\widetilde{\operatorname{EXP}}^{\mathrm{A}}$ ATL3 and CABA SSTA is mostly negative ( -9 days on average over the 12 experiments), CABA leading ATL3 variability. Similarly, consistently with $\overline{\mathrm{EXP}}^{A}$ and $\mathrm{CROCO}{ }^{\mathrm{LONG}}$ composites, on average over the $12 \widetilde{\mathrm{EXP}}^{\mathrm{A}}$ experiments, CABA SLA leads ATL3 SLA by 9 days, that is, a backward shift of $\sim 3$ weeks compared to $\widetilde{\operatorname{EXP}}^{\mathrm{W}}$ results.

In conclusion, our model results show that the wind-stress variability in the southeastern Atlantic increases the magnitude of the coastal warm event by $\sim 25 \%$ in the surface and subsurface layers. It also drastically 


\section{ERA40 and ERA-Interim SLP and $10 \mathrm{~m}$-winds composites}

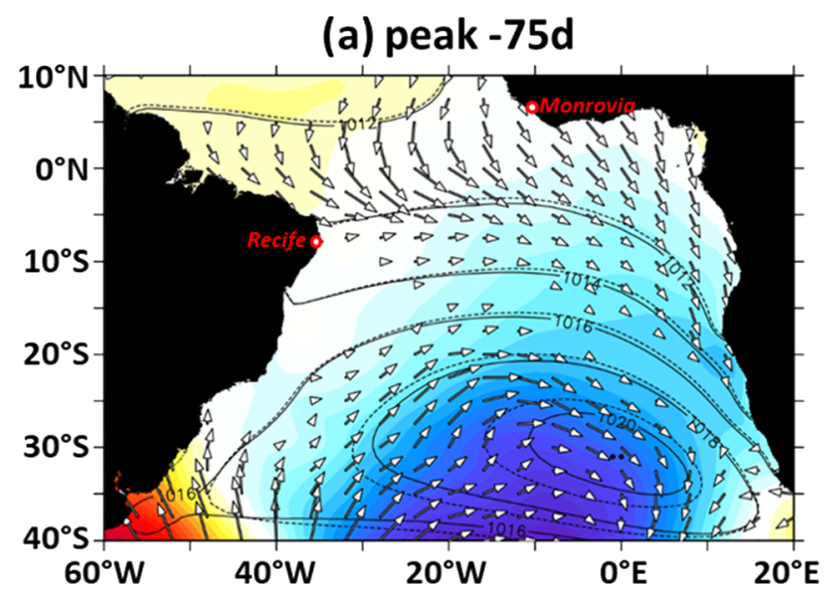

(b) peak $+30 d$

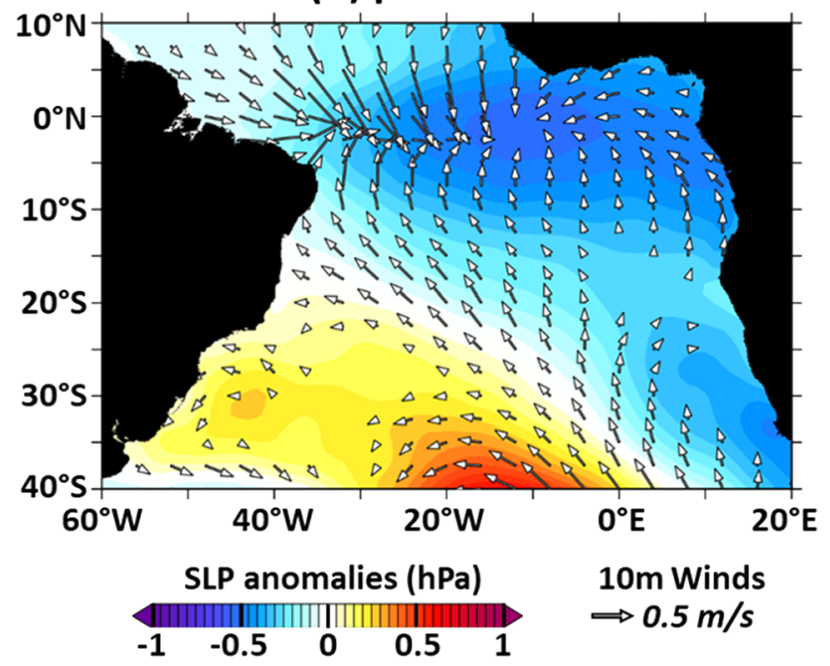

Figure 13. Surface circulation from ERA40 and ERA-Interim data. Composites at (a) peak -75 days and (b) peak +30 days of Sea Level Pressure (SLP) anomalies (colors, hPa) and 10-m winds (arrows, m/s). On top panel, the warm event composite of SLP is displayed in plain contours, as compared to the normal conditions (dashed contours). impacts the timing of the coastal fluctuations off Angola, shifting both the onset and the demise to earlier. Note that, in $\overline{\mathrm{EXP}}^{A}$ and $\widetilde{\mathrm{EXP}}$, we did not perturb the surface wind amplitude. The latter would modulate the evaporation, in phase with the meridional wind-stress anomalies (cf. Figure 11a), most likely increasing the shifting of the event and consequently increasing the delay between CABA and ATL3 warm events, in better agreement $\mathrm{CROCO}^{\mathrm{LONG}}$ SSTA lag-correlation analysis ( -16 days in Figure 2) or composites (-24 days in Figure 4a).

Interestingly, we found that the CABA meridional wind-stress anomalies reverse exactly in phase with the maximum in zonal-wind stress anomalies in the WCEA. In the following section, we will make a closer inspection of the surface circulation in order to disclose a possible large-scale connection between the anomalous winds in the western-equatorial Atlantic and the atmospheric surface circulation along the coast of southwestern Africa.

\subsection{Wind Circulation Analysis}

In this section, we examine the anomalous atmospheric circulation associated with the warm events. We showed in section 5.4 that the coastal wind-stress forcing is crucial for the delay between coastal and eastern-equatorial warm events. We aim at investigating whether the anomalous coastal surface wind fluctuations and their change in direction 15 days before the SSTA peak in the cold tongue region (cf. Figures $4 \mathrm{~d}$ and 11a) is linked to a large-scale atmospheric circulation pattern. We focus on the onset and demise of the coastal warm event.

Figure 13a presents the composite map of interannual anomalies of SLP (colors) and 10-m winds (arrows) during the onset of the coastal event (at peak -75 days). It shows that prior to the development of the warm event, the SLP is substantially weaker than the normal conditions South of a line connecting Recife, (Brazil, $\sim\left[35^{\circ} \mathrm{W} ; 8^{\circ} \mathrm{S}\right]$ ) to Monrovia (Liberia, $\sim\left[11^{\circ} \mathrm{W} ; 6^{\circ} \mathrm{N}\right]$ ). Positive anomalies are found in the northern domain, while maximum negative SLP anomalies are located South of the core of the South-Atlantic High, slightly extending to the coast of Africa, South of $20^{\circ} \mathrm{S}$. The composite shows that the magnitude of the SAA is weakened, but its position remains unchanged, as illustrated by the warm event mean SLP isobars (plain contours) compared to the normal conditions (dashed contours). This is in agreement with the results of $\mathrm{Hu}$ and Huang (2007), Lübbecke et al. (2010, 2014), and Richter et al. (2010). As a result, the atmospheric circulation portrays strong cyclonic anomalous winds close to the core of the SAA, associated with a moderate off-shore warming (cf. Figure 4c) due to reduced evaporation. At the periphery of the anticyclone, anomalous geostrophic motions affect both the trade winds and the coastal winds off southwestern Africa (cf. Figures 4b and 13a). Off Angola and Namibia, northerly wind anomalies trigger an early coastal warming (cf. Figure 4b) presumably through local processes (downwelling and reduced evaporation). Meanwhile, in the equatorial band, the warming starts in the West (modulation of the evaporation) and positive SSTA in the eastern-equatorial Atlantic develop a couple of weeks later, associated with the remotely forced downwelling EKW. The subsequent CTWs then reinforce the local coastal warming as described in section 5.4.

We further showed that the early demise of the coastal warm event is controlled by the change in direction of the anomalous meridional surface wind-stress off Angola (cf. Figure 11a), as suggested by Hu and Huang (2007). The latter is in phase with the maximum of zonal wind-stress anomalies in the WCEA (cf. Figure 5a). A closer inspection of the basin-scale surface circulation reveals that an 
anomalous convergent circulation develops over the Atlantic Niño SSTA, associated with coastal anomalous southerly winds off southwestern Africa (cf. Figures 3e-3g). A composite of the atmospheric circulation at peak +30 days is presented in Figure 13b. Negative SLP anomalies are colocalized with the interannual warming of the ocean surface layer and are maximum in the equatorial band at $\sim 10^{\circ} \mathrm{W}$. Positive SSTA over the $\left[40^{\circ} \mathrm{W}-10^{\circ} \mathrm{W} ; 3^{\circ} \mathrm{S}-3^{\circ} \mathrm{N}\right]$ equatorial band are associated with anomalous upward vertical flows of $\sim 2.10^{-2} \mathrm{~Pa} / \mathrm{s}$ in the overlying atmosphere (within 900-300 mb). It yields an anomalous convergence of the surface winds which converge towards the lowest SLP anomalies (cf. arrows in Figure 13b) and reinforce WCEA zonal wind-stress anomalies, consistent with the Bjerknes feedback. This anomalous convergence of air also affects the Hadley circulation and drives equatorward wind anomalies along the coast of southwestern Africa, consistent with the results of Hu and Huang (2007). The latter stop prematurely the remotely forced coastal event (cf. section 5.4) before cold tongue SSTAs reach their maximum.

This result brings to light another level of connection between the interannual variability in the equatorial band and the SSTA fluctuations in the coastal band. Both events are mostly triggered by the modulation of the trade winds in the WCEA that drives EKW and subsequent CTW propagations. Our results imply that ocean-atmosphere coupling in the equatorial band may also affect the local forcing along the coast of southwestern Africa which in turn controls the magnitude and timing of the coastal events. In particular, we note that the change in direction in the coastal meridional wind-stress anomalies occurs when the CROCO ${ }^{\text {LONG }}$ SSTA composite averaged in the KATL3 box exceeds $1^{\circ} \mathrm{C}$. In line with this, one can wonder if the level of magnitude of the SSTA in the eastern-equatorial Atlantic can be linked to the delay between equatorial and coastal events. This will be discussed in the following section.

\section{Summary, Discussion, and Conclusions}

Using targeted model experiments with a Tropical Atlantic Ocean model, we tested numerous hypotheses raised by previous studies to explain why coastal SSTA variability off Angola tends to precede the eastern-equatorial SSTA fluctuations by $\sim 1$ month. We simulated warm equatorial and coastal events triggered by idealized wind-stress perturbations over a controlled ocean mean-state (stationary and then seasonally varying). This wind-stress forcing was estimated based on a composite analysis of 15 extreme eastern-equatorial warm events and mainly consists of a weakening of the trade winds in the western-central equatorial Atlantic. Notably, the average of 15 singular forcings that are not in phase with one another results in a wind-stress forcing smoother than the actual forcing of any observed event. It, however, provided a realistic simulation of Atlantic and Benguela Niño events. This study presented, therefore, a big-picture analysis of the Tropical Atlantic interannual variability and the reader is thus reminded that each interannual event is peculiar and subject, in particular, to a strong modulation by the intraseasonal variability that was not addressed in the present work.

We first explored the processes associated with a remotely forced scenario in which equatorial and coastal SSTA variations are driven by the propagation of downwelling waves. Our model simulations highlighted the marked seasonal modulation of the remotely forced SSTA variability in the cold tongue region, with a thermal response four times stronger when the WCEA interannual forcing is applied in the MJJ season than in NDJ (Figure 8b), while the warming in the subsurface remains fairly constant. In agreement with Keenlyside and Latif (2007), in MJJ the model subsurface/surface coupling is most effective: The seasonal equatorial upwelling is strong, and the thermocline is shallow, close to the base of the mixed layer. In MJJ, the equatorial Atlantic will, therefore, be prone to an effective penetration of the subsurface temperature anomalies to the surface layer and to a strong positive feedback from ocean-atmosphere interactions through Bjerknes and Ekman processes. However, the surface conditions in boreal spring (yielding MJJ SSTA) are not favorable to a stronger momentum transfer to the ocean. Analyses with Kondo (1975) bulk formulation indeed show that WCEA anomalous surface wind fluctuations in boreal spring (yielding MJJ SSTA) trigger a wind-stress response that is $15 \%$ to $20 \%$ weaker than momentum fluxes estimated with mean annual parameters (SST, wind speed, $2 \mathrm{~m}$ air temperature and humidity). Our results show that the delay between cold-tongue SSTA and WCEA wind-stress anomalies is primarily controlled by the phase speed of the EKW propagations, rather than by the speed of thermodynamic processes. 
Off Angola, the seasonal phasing of the equatorially forced coastal warming is not as strong as in the cold tongue region. In the FMA season, the alongshore warming is indeed only 15\% stronger than the coastal SSTA maxima averaged for the $12 \widetilde{\mathrm{EXP}}^{\mathrm{W}}$ experiments (Figure 9b). In CABA, the temperature anomalies are also more homogeneous above the thermocline compared to the eastern-equatorial sector. Our results show that the seasonal modulation of the coastal warming is associated with the stronger meridional thermal gradients in the FMA season, rather than favorable coastal vertical stratification or upwelling conditions. Furthermore, compared to the eastern equatorial sector, the weaker seasonal phasing of the coastal warming depending on the month at which the remote wind-stress perturbations are applied suggests that the seasonality of the dominant forcing mechanisms play a larger role in shaping the seasonal phasing of the Benguela Niños. The timing of the remotely forced coastal thermal response off Angola strays from the dynamical response, highlighting the importance of nonlinear and thermodynamic processes.

Notably, the amplitude of the remotely forced simulated warm events, both in the equatorial and coastal regions, is relatively weak compared to the observations or to our most realistic experiment. This can be attributed to our composited interannual wind-stress forcing that averages the 15 warmest cold tongue events whose forcings are not in phase with one another. The peak of the WCEA composite wind-stress is indeed 20\% lower than the average of the maximum of each individual forcing. It is less than half of the WCEA wind-stress maximum for the 1968 and 1974 Atlantic Niños. The reduced amplitude of the surface thermal response is also due to the use of bulk formulations to estimate the surface turbulent heat fluxes. The latter dampen the SSTA fluctuations through Newtonian cooling. Thus, one of the limitations of this study is that the model experiments have been conducted in a forced-context. On the one hand, this approach allowed us to fully control the model remote and local surface forcings, but on the other hand, the heat fluxes cannot react to the ocean state.

Our results showed that, in a remotely forced scenario, with the interannual wind-stress forcing restricted to the western-central equatorial Atlantic, the model yields equatorial events leading the coastal variability off Angola, consistent with the propagation path of the remotely forced waves. This excludes the remotely forced dynamics and the ocean mean-state characteristics as the main process controlling the timing of the events. We, however, found substantial semiannual variations of the lags between eastern-equatorial and coastal SSTA fluctuations, indicating that the seasonal modulation of the ocean mean-state can impact the timing of the SSTA fluctuations. Part of this seasonal variability can be directly attributed to the linear dynamics (baroclinic modal contributions and phase-speed of the waves) shaped by the variability of the vertical temperature stratification (Bachèlery et al., 2020; Illig \& Bachèlery, 2019). The seasonal modulation of the surface response is also impacted by the speed of the thermodynamic processes (Lübbecke et al., 2010; Zelle et al., 2004).

Only when wind-stress anomalies are prescribed over the whole domain, that is, including the coastal fringe, idealized model experiments simulated coastal warm events off Angola that precede the ones in the cold tongue region. Our results show that this behavior is associated with the coastal meridional wind-stress variability which controls the timing of the coastal events, shifting both the onset and the demise to earlier. Coastal wind-stress perturbations trigger a backward shift of the timing between ATL3 and CABA surface and subsurface temperature variability of 1.25 months, compared to the experiment without any interannual coastal wind-stress forcing. They also increase the magnitude of the coastal warm event by $\sim 25 \%$ both in the surface and subsurface layers. In line with Bachèlery et al. (2016, 2020), our results indicate that the WCEA remote forcing remains the main driver of coastal interannual events, the local wind-stress forcing modulating their timing and amplitude. The phenology of warm coastal events can be decomposed in 4 phases, as illustrated in Figure 14. First, a weakened SAA (Figure 14a) yields coastal northerly wind anomalies that initiate warm conditions along the coast off Angola and Namibia, before the onset of the warming in the cold tongue region. These coastal winds are almost concomitant with a relaxation of the trade-winds in the western-central equatorial basin, associated with a weak warming in the WCEA. Positive SSTAs in the eastern-equatorial Atlantic develop a couple of weeks later, associated with remotely forced downwelling EKW (Figure 14b). Based on the SLP anomalies and the surface wind pattern, we argued that the initial changes in alongshore and equatorial winds are both associated with a weakening of the South-Atlantic subtropical High, while Hu and Huang (2007) suggested that air-sea interactions along the coast may drive the westerly wind anomalies 
(a) Weakening of the SAA and local warmings

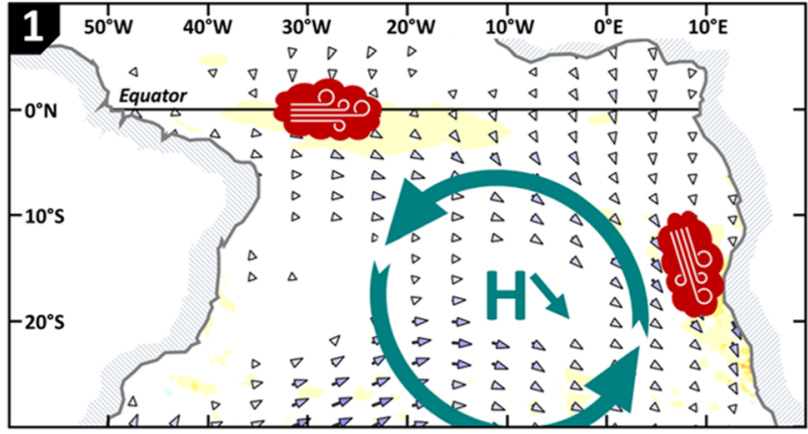

(c) Bjerknes feedback and coastal $\tau_{\mathrm{y}}$ a inversion

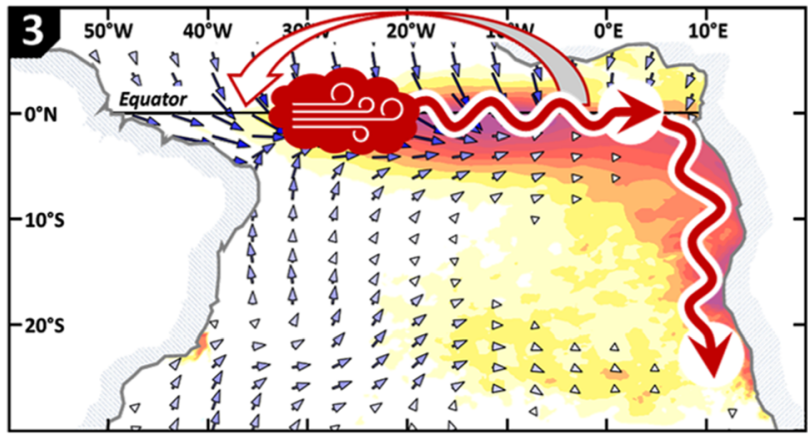

(b) Wave propagation: [Remote + local] coastal warming

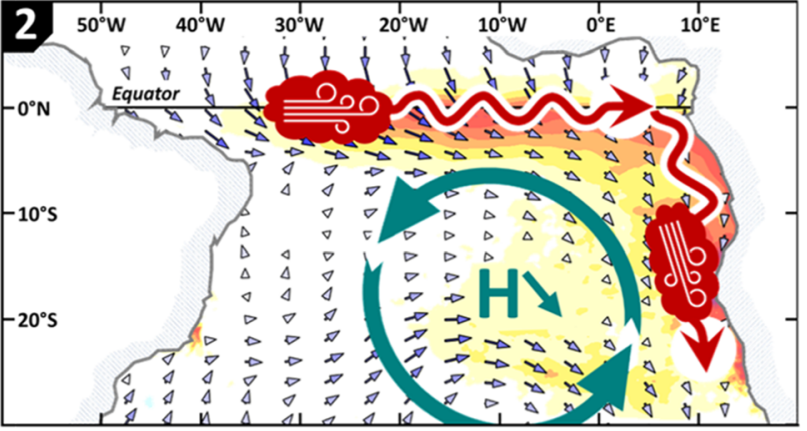

(d) Converging circulation and coastal warming demise

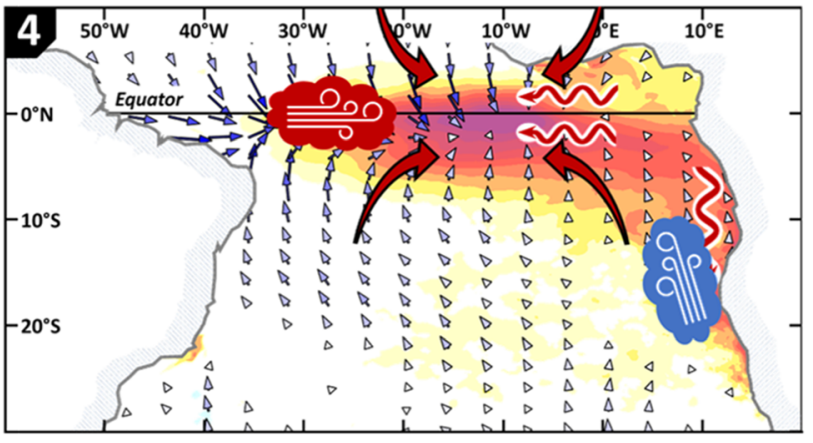

Figure 14. Set of schematics illustrating the coastal event phenology. Colors (arrows) represent SST (wind-stress) anomalies from Figure 4. Panel (a) shows the weakening of the South-Atlantic Anticyclone, associated with positive zonal wind-stress anomalies in the western-central equatorial Atlantic and negative coastal meridional wind-stress anomalies off Angola. Panel (b) emphasizes the remotely forced warming triggered by eastward-propagating downwelling EKW and subsequent poleward CTW. Panel (c) symbolizes the establishment of the ocean-atmosphere interactions accompanying the eastern-equatorial warming, namely, the Bjerknes feedback and the reverse of the coastal meridional wind-stress anomalies off southwestern Africa. Panel (d) illustrates the reflected equatorial downwelling Rossby waves which amplify the eastern-equatorial warming and the surface atmospheric converging circulation over the eastern-equatorial warm event underlying the reinforcement of the upwelling-favorable coastal meridional wind-stress and causing the early demise of the remotely forced coastal warm event.

along the equator. In our opinion, although we detected coastal SLP anomalies associated with the coastal warming, the coastal SSTAs are still weak when the broad basin-wide weakening of the trade winds begins (Figure 14a). Then, the coastal warming magnifies (Figure 14b), largely triggered by the equatorially forced downwelling CTW propagations and also intensified by the local surface circulation. Afterward, the alongshore surface wind anomalies reverse (Figure 14c). This anomalous upwelling-favorable forcing weakens the SSTA along the southeastern coast and stops the remotely forced coastal event prematurely before the eastern-equatorial SSTAs, amplified by reflected equatorial downwelling Rossby waves, reach their maximum (Figure 14d). In agreement with $\mathrm{Hu}$ and Huang (2007), we uncovered the development of a low-level convergence centered over the eastern-equatorial warming. It enhances the westerly anomalies in the WCEA due to equatorial feedbacks and also drives the anomalous alongshore winds equatorward from the equator to $20^{\circ} \mathrm{S}$ (Figures $13 \mathrm{~b}$ and $14 \mathrm{~d}$ ). Notably, South of $20^{\circ} \mathrm{S}$, the coastal winds do not appear drawn towards the eastern-equatorial convective center. This suggests that the equatorially forced CTWs might dominate the coastal interannual variability along the coast of Namibia and South Africa. The associated SSTA fluctuations would thus peak later than along the coast of Angola. This could explain the C-shaped pattern observed in the delay between equatorial and coastal SSTAs as a function of the latitude uncovered in Figures $1 \mathrm{~b}$ and 2 (circles and squares).

Interestingly, the analysis of the SLA of our most realistic simulation $\left(\mathrm{CROCO}^{\mathrm{LONG}}\right)$ revealed that when analyzing the entire timeseries the CABA SLA variability lags the eastern-equatorial SLA fluctuations by 14 days (lag-correlation analyses, cf. triangles in Figure 2), while the composite analysis (Figure 4a) highlights SLA CABA preceding ATL3 SLA by 18 days. To explain this inconsistency, we can review the time sequence 
of the idealized experiments. We reported that model experiments in which remotely forced EKW-CTW that are not associated with ocean-atmosphere interactions and coastal meridional wind-stress anomalies (as artificially simulated in $\overline{\mathrm{EXP}}^{W}$ and $\widetilde{\mathrm{EXP}}^{\mathrm{W}}$ ) propagate freely, impacting the eastern-equatorial variability before triggering coastal SLA and SSTA variations (Figures 6 and 10). Conversely, in $\overline{\mathrm{EXP}}^{A}$ and $\widetilde{\mathrm{EXP}}{ }^{\mathrm{A}}$, interannual alongshore wind-stress perturbations are based on the atmospheric circulation associated with extreme equatorial warm events and yield coastal SLA and SSTA variability preceding the equatorial SLA fluctuations (Figures 11d and 12c). This suggests that downwelling EKW propagations that are associated with a strong surface thermal response in the eastern-equatorial sector (in MJJ for instance) provoke the development of a convergent circulation over the cold tongue region, driving upwelling-favorable along-shore winds and therefore triggering coastal SLA preceding equatorial fluctuations. This explains why the composite analysis of Figure 4 which grasps only extreme eastern-equatorial warm events is associated with negative lags for both SLA and SSTA variabilities. Contrastingly, the SLA analysis conducted in Figure 2 (triangles) captures both types of waves and yields positive lags (ATL3 leading CABA) in agreement with Bachèlery et al. (2020). Meanwhile, lag-correlation analyses of SSTA favors intense SSTA events associated with ocean-atmosphere interactions and lead to negative lags (cf. Figure 1b, circles in Figures 2 and 4).

Using idealized model experiments, we showed that interannual coastal wind-stress fluctuations off southwestern Africa can considerably impact the timing of coastal temperature fluctuations. This local forcing can shift the development and the demise of the coastal event backward by more than 1 month, such as the coastal SST event precedes the anomalous warming in the eastern-equatorial sector by 9 days (Figures 11d and $12 \mathrm{c}$ ). However, the simulated time-lapse remains notably small compared to the observations (Figure 1, 27 days). On the one hand, there might be an overestimation of the delay estimated with OISST data due to the gridding method that smoothes the signal in time and space. On the other hand, the discrepancy between our idealized experiment results and the observations can be attributed to the model biases, since our most realistic experiment (CROCO ${ }^{\mathrm{LONG}}$ ) already underestimated the delay (Figure 2, 16 days). In particular, as diagnosed in the supporting information, the equatorial and coastal thermoclines are deeper and more diffuse than the observations, which can impact the phase speed of the EKW and CTW. Besides, the relatively low resolution of the wind-stress forcing in the coastal fringe prevents a realistic wind drop-off zone, which can impact the ocean mean-state and the interannual coastal variability. The underestimation of the delay between equatorial and coastal SSTA variabilities is further amplified by the idealized set-up of the targeted experiments we conducted, namely the smoothed momentum forcing, the absence of coastal interannual evaporation or ocean-atmosphere interactions.

In conclusion, this study showed evidence that Atlantic and Benguela Niños are connected via an ocean teleconnection associated with equatorial and coastal wave propagations, but they are also tied by a large-scale atmospheric circulation and ocean-atmosphere interactions. Our results suggest that the timing of the coastal event is directly connected to the amplitude of the warming in the cold tongue region. Similarly, the warmer the eastern-equatorial SSTA, the more intense the convergent circulation, resulting in the alongshore wind anomalies further to the south being drawn towards the equator. In this context, the seasonal-phasing of the cold tongue SSTA variability may modulate the alongshore wind variability and thus the timing of the coastal variability with a possible dependence on the latitude of the coastal region. However, this connection can only be diagnosed in an ocean-atmosphere coupled context, in which surface momentum and heat fluxes will respond to the ocean state. Thus, our future work will focus on the development of a coupled model configuration of the Tropical Atlantic in order to analyze the ocean and atmosphere connection between Atlantic and Benguela Niño events and to appraise to which extent they can be viewed as one single mode of variability. In particular, targeted model experiments will allow evaluating if the coastal SSTA variability can modulate the trade wind in the WCEA, as suggested by $\mathrm{Hu}$ and Huang (2007).

\section{Data Availability Statement}

CROCO and CROCO_TOOLS can be downloaded from https://www.croco-ocean.org. Ferret is a product of NOAA's Pacific Marine Environmental Laboratory, available at http://ferret.pmel.noaa.gov/Ferret. NOAA OISST and AVISO Altimetric data, DFS, and ECMWF ERA fields, CARS2009 and WOA monthly climatologies, and GEBCO topography are freely available to the public on the dedicated websites of these programs. 
CROCO model outputs used in this study are freely available at https://dx.doi.org/10.6084/m9. figshare.12727670.

\section{Acronyms}

$\begin{array}{ll}\text { ABA } & \text { Angola-Benguela Area }\left(\left[8^{\circ} \mathrm{E}-\text { coast, } 10^{\circ} \mathrm{S}-20^{\circ} \mathrm{S}\right]\right) \\ \text { ABFZ } & \text { Angola Benguela Frontal Zone } \\ \text { ATL3 } & \left(20^{\circ} \mathrm{W}-0^{\circ} \mathrm{E} ; 3^{\circ} \mathrm{S}-3^{\circ} \mathrm{N}\right) \text { domain } \\ \text { CARS2009 } & 2009 \text { CSIRO Atlas of Regional Seas climaology } \\ \text { CROCO } & \text { Coastal and Regional Ocean COmmunity model } \\ \text { CTW } & \text { Costal Trapped Wave } \\ \text { CABA } & \text { Coastal Angola Benguela Area }\left(\left[2^{\circ} \text {-width coastal fringe, } 10^{\circ} \mathrm{S}-20^{\circ} \mathrm{S}\right]\right) \\ \text { DFS } & \text { DRAKKAR Forcing Set } \\ \text { EKW } & \text { Equatorial Kelvin Wave } \\ \text { FFT } & \text { Fast Fourier Transform } \\ \text { FMA } & \text { February-March-April } \\ \text { KATL3 } & \left.\left.\text { Kelvin-ATL3 domain ([20 }{ }^{\circ} \mathrm{W}-0^{\circ} \mathrm{E} ; 1^{\circ} \mathrm{S}-1^{\circ} \mathrm{N}\right]\right) \\ \text { MJJ } & \text { May-June-July } \\ \text { NDJ } & \text { November-December-January } \\ \text { OBC } & \text { Open Boundary Conditions } \\ \text { SAA } & \text { South-Atlantic Anticyclone } \\ \text { SL } & \text { Sea Level } \\ \text { SLA } & \text { Sea Level interannual Anomaly } \\ \text { SLP } & \text { Sea Level Pressure } \\ \text { SLPA } & \text { Sea Level Pressure Anomaly } \\ \text { SSS } & \text { Sea Surface Salinity } \\ \text { SST } & \text { Sea Surface Temperature } \\ \text { SSTA } & \text { Sea Surface Temperature Anomaly } \\ \text { STD } & \text { STandard Deviation } \\ \text { WCEA } & \text { Western-Central Equatorial Atlantic }\left(\left[40^{\circ} \mathrm{W}-20^{\circ} \mathrm{W} ; 3^{\circ} \mathrm{S}-3^{\circ} \mathrm{N}\right]\right) \\ \end{array}$

\section{Acknowledgments}

We would like to thank Drs. W. Llovel, N. Hall, and L. Renault for fruitful discussions on the contribution of thermal expansion to SLA, the large-scale atmospheric pattern, and the ocean-atmosphere interactions. Special thanks are addressed to N. Salonen for participating in the sensitivity tests at an early stage of this work. Marie-Lou Bachèlery has received funding by the NRF SARCHI chair on "modeling ocean-atmosphereland interactions", the Nansen Tutu

Centre, and the EU H2020 TRIATLAS project under the grant agreement 817578. This work is a contribution to the BANINO project (03F0795A) funded by the German Federal Ministry of Education and Research. Model computations were performed on CALMIP computer at University Paul Sabatier (Toulouse, France, CALMIP project 19002). CROCO model grid, forcing, and initial conditions were built using the CROCO_Tools software (Penven et al., 2008). Authors wish to acknowledge use of the PyFerret program for analysis and graphics in this paper.

\section{References}

Bachèlery, M. L., Illig, S., \& Dadou, I. (2016). Interannual variability in the South-East Atlantic Ocean, focusing on the Benguela upwelling system: Remote versus local forcing. Journal of Geophysical Research: Oceans, 121, 284-310. https://doi.org/10.1002/2015JC011168

Bachèlery, M. L., Illig, S., \& Rouault, M. (2020). Interannual coastal trapped waves in the Angola-Benguela upwelling system and Benguela Niño and Niña events. Journal of Marine Systems, 203. https://doi.org/10.1016/j.jmarsys.2019.103262

Binet, D., Gobert, B., \& Maloueki, L. (2001). El Niño-like warm events in the Eastern Atlantic $\left(6^{\circ} \mathrm{N}, 20^{\circ} \mathrm{S}\right)$ and fish availability from Congo to Angola (1964-1999). Aquatic Living Resources, 14(2), 99-113. https://doi.org/10.1016/S0990-7440(01)01105-6

Boyer, D. C., Boyer, H. J., Fossen, I., \& Kreiner, A. (2001). Changes in abundance of the northern Benguela sardine stock during the decade 1990-2000, with comments on the relative importance of fishing and the environment. South African Journal of Marine Science, 23, 76-84.

Brandt, P., Caniaux, G., Bourlès, B., Lazar, A., Dengler, M., Funk, A., et al. (2011). Equatorial upper-ocean dynamics and their interaction with the West African monsoon. Atmospheric Science Letters, 12(1), 24-30. https://doi.org/10.1002/asl.287

Burls, N. J., Reason, C. J. C., Penven, P., \& Philander, S. G. (2011). Similarities between the tropical Atlantic seasonal cycle and ENSO: An energetics perspective. Journal of Geophysical Research, 116, C11010. https://doi.org/10.1029/2011JC007164

Cabos, W., de la Vara, A., \& Koseki, S. (2019). Tropical Atlantic variability: Observations and modelling. Atmosphere, 10(9), 502. https://doi. org/10.3390/atmos10090502

Carton, J., \& Huang, B. (1994). Warm events in the tropical Atlantic. Journal of Physical Oceanography, 24(5), 888-903. https://doi.org/ 10.1175/1520-0485(1994)024<0888:WEITTA >2.0.CO;2

Clarke, A. J. (1983). The reflection of equatorial waves from oceanic boundaries. Journal of Physical Oceanography, 13(7), $1193-1207$. https://doi.org/10.1175/1520-0485(1983)013<1193:TROEWF >2.0.CO;2

Clarke, A. J., \& Van Gorder, S. (1986). A method for estimating wind-driven frictional, time-dependent, stratified shelf and slope water flow. Journal of Physical Oceanography, 16(6), 1013-1028. https://doi.org/10.1175/1520-0485(1986)016<1013:AMFEWD>2.0.CO;2

Debreu, L., Marchesiello, P., Penven, P., \& Cambon, G. (2012). Two-way nesting in split-explicit ocean models: Algorithms, implementation and validation. Ocean Model, 49-50, 1-21. https://doi.org/10.1016/j.ocemod.2012.03.003

Dee, D. P., Uppala, S. M., Simmons, A. J., Berrisford, P., Poli, P., Kobayashi, S., et al. (2011). The ERA-interim reanalysis: Configuration and performance of the data assimilation system. Quarterly Journal of the Royal Meteorological Society, 137(656), 553-597. https://doi.org/ $10.1002 /$ qj. 828

Dewitte, B. (2000). Sensitivity of an intermediate ocean-atmosphere coupled model of the tropical Pacific to its oceanic vertical structure. Journal of Climate, 13(13), 2363-2388. https://doi.org/10.1175/1520-0442(2000)013<2363:SOAIOA >2.0.CO;2 
Ding, H., Keenlyside, N., \& Latif, M. (2009). Seasonal cycle in the upper equatorial Atlantic Ocean. Journal of Geophysical Research, 114, C09016. https://doi.org/10.1029/2009JC005418

Dunn, J. (2009). CARS 2009: CSIRO atlas of regional seas, mar. lab., Commonw. Sci. And Ind. Res. Organ., Hobart, Tasmania, Australia. Dussin, R., Barnier, B., \& Brodeau, L. (2016). The making of DRAKKAR forcing set DFS5, DRAKKAR/MyOcean rep. 01-04-16, Laboratoire de Glaciologie et Géophysique de l'Environnement, Grenoble, France.

Florenchie, P., Lutjeharms, J. R. E., Reason, C. J. C., Masson, S., \& Rouault, M. (2003). The source of Benguela Niños in the South Atlantic Ocean. Geophysical Research Letters, 30(10), 1505. https://doi.org/10.1029/2003GL017172

Florenchie, P., Reason, C. J. C., Lutjeharms, J. R. E., \& Rouault, M. (2004). Evolution of interannual warm and cold events in the Southeast Atlantic Ocean. Journal of Climate, 17(12), 2318-2334. https://doi.org/10.1175/1520-0442(2004)017<2318:EOIWAC>2.0.CO;2

Hu, Z.-Z., \& Huang, B. (2007). Physical processes associated with the tropical Atlantic SST gradient during the anomalous evolution in the southeastern ocean. Journal of Climate, 20(14), 3366-3378. https://doi.org/10.1175/JCLI4189.1

Illig, S., \& Bachèlery, M.-L. (2019). Propagation of subseasonal equatorially-forced coastal trapped waves down to the Benguela upwelling system. Scientific Reports, 9(1), 5306. https://doi.org/10.1038/s41598-019-41847-1

Illig, S., Cadier, E., Bachèlery, M.-L., \& Kersalé, M. (2018). Subseasonal coastal-trapped wave propagations in the Southeastern Pacific and Atlantic oceans: 1. A new approach to estimate wave amplitude. Journal of Geophysical Research: Oceans, 123, 3915-3941. https://doi. $\operatorname{org} / 10.1029 / 2017 \mathrm{JC} 013539$

Illig, S., \& Dewitte, B. (2006). Local coupled equatorial variability versus remote ENSO forcing in an intermediate coupled model of the tropical Atlantic. Journal of Climate, 19(20), 5227-5252. https://doi.org/10.1175/JCLI3922.1

Illig, S., Dewitte, B., Ayoub, N., du Penhoat, Y., Reverdin, G., Mey, P. D., et al. (2004). Interannual long equatorial waves in the tropical Atlantic from a high-resolution ocean general circulation model experiment in 1981-2000. Journal of Geophysical Research, 109, C02022. https://doi.org/10.1029/2003JC001771

Illig, S., Gushchina, D., Dewitte, B., Ayoub, N., \& du Penhoat, Y. (2006). The 1996 equatorial Atlantic warm event: Origin and mechanisms. Geophysical Research Letters, 33, L09701. https://doi.org/10.1029/2005GL025632

Imbol Koungue, R. A., Illig, S., \& Rouault, M. (2017). Role of interannual kelvin wave propagations in the equatorial Atlantic on the Angola Benguela current system. Journal of Geophysical Research: Oceans, 122, 4685-4703. https://doi.org/10.1002/2016JC012463

Imbol Koungue, R. A., Rouault, M., Illig, S., Rouault, M., Brandt, P., \& Jouanno, J. (2019). Benguela Niños and Benguela Niñas in forced ocean simulation from 1958 to 2015. Journal of Geophysical Research: Oceans, 124, 5923-5951. https://doi.org/10.1029/2019JC015013

Keenlyside, N., \& Latif, M. (2007). Understanding equatorial Atlantic interannual variability. Journal of Climate, 20(1), 131-142. https:// doi.org/10.1175/JCLI3992.1

Kondo, J. (1975). Air-sea bulk transfer coefficients in diabatic conditions. Boundary-Layer Meteorology, 9(1), 91-112. https://doi.org/ $10.1007 /$ BF00232256

Lübbecke, J. F., Böning, C. W., Keenlyside, N. S., \& Xie, S.-P. (2010). On the connection between Benguela and equatorial Atlantic Niños and the role of the South Atlantic anticyclone. Journal of Geophysical Research, 115, C09015. https://doi.org/10.1029/ 2009JC005964

Lübbecke, J. F., Brandt, P., Dengler, M., Kopte, R., Lüdke, J., Richter, I., et al. (2019). Causes and evolution of the southeastern tropical Atlantic warm event in early 2016. Climate Dynamics, 53(1-2), 261-274. https://doi.org/10.1007/s00382-018-4582-8

Lübbecke, J. F., Burls, N. J., Reason, C. J. C., \& McPhaden, M. J. (2014). Variability in the South Atlantic anticyclone and the Atlantic Niño mode. Journal of Climate, 27(21), 8135-8150. https://doi.org/10.1175/JCLI-D-14-00202.1

Lübbecke, J. F., Rodríguez-Fonseca, B., Richter, I., Martín-Rey Marta, M., Losada, T., Polo, I., \& Keenlyside, N. S. (2018). Equatorial Atlantic variability-Modes, mechanisms, and global teleconnections. WIREs Climate Change, 9(4), e527. https://doi.org/10.1002/ wcc. 527

Lutz, K., Jacobeit, J., \& Rathmann, J. (2015). Atlantic warm and cold water events and impact on African west coast precipitation. International Journal of Climatology, 35(1), 128-141. https://doi.org/10.1002/joc.3969

Martín-Rey, M., Polo, I., Rodríguez-Fonseca, B., Losada, T., \& Lazar, A. (2018). Is there evidence of changes in tropical Atlantic variability modes under AMO phases in the observational record? Journal of Climate, 31(2), 515-536. https://doi.org/10.1175/JCLI-D-16-0459.1

Mohino, E., Rodríguez-Fonseca, B., Losada, T., Gervois, S., Janicot, S., Bader, J., \& Chauvin, F. (2011). Changes in the interannual SST-forced signals on West African rainfall. AGCM intercomparison. Climate Dynamics, 37(9-10), 1707-1725. https://doi.org/10.1007/ s00382-011-1093-2

Moore, D. W. Planetary-gravity waves in an equatorial ocean. Ph.D. thesis, Harvard University. (1968).

Mosquera-Vásquez, K., Dewitte, B., \& Illig, S. (2014). The Central Pacific El Niño intraseasonal kelvin wave. Journal of Geophysical Research: Oceans, 119, 6605-6621. https://doi.org/10.1002/2014JC010044

Okumura, Y., \& Xie, S. (2004). Interaction of the Atlantic equatorial cold tongue and the African monsoon. Journal of Climate, 17(18), 3589-3602. https://doi.org/10.1175/1520-0442(2004)017<3589:IOTAEC >2.0.CO;2

Okumura, Y., \& Xie, S. (2006). Some overlooked features of tropical Atlantic climate leading to a new Niño-like phenomenon. Journal of Climate, 19(22), 5859-5874. https://doi.org/10.1175/JCLI3928.1

Penven, P., Debreu, L., Marchesiello, P., \& McWilliams, J. C. (2006). Evaluation and application of the ROMS 1-way embedding procedure to the Central California upwelling system. Ocean Model, 12(1-2), 157-187. https://doi.org/10.1016/j.ocemod.2005.05.002

Penven, P., Marchesiello, P., Debreu, L., \& Lefevre, J. (2008). Software tools for pre- and post-processing of oceanic regional simulations. Environmental Modelling \& Software, 23(5), 660-662. https://doi.org/10.1016/j.envsoft.2007.07.004

Planton, Y., Voldoire, A., Giordani, H., \& Caniaux, G. (2018). Main processes of the Atlantic cold tongue interannual variability. Climate Dynamics, Springer Verlag, 2018, 50(5-6), 1495-1512. https://doi.org/10.1007/s00382-017-3701-2

Polo, I., Rodríguez-Fonseca, B., Losada, T., \& Garcia-Serrano, J. (2008). Tropical Atlantic variability modes (1979-2002). Part I: Time-evolving SST modes related to West African rainfall. Journal of Climate, 21(24), 6457-6475. https://doi.org/10.1175/2008JCI2607.1

Reynolds, R. W., Smith, T. M., Liu, C., Chelton, D. B., Casey, K. S., \& Schlax, M. G. (2007). Daily high-resolution-blended analyses for sea surface temperature. Journal of Climate, 20(22), 5473-5496. https://doi.org/10.1175/2007JCLI1824.1

Richter, I., Behera, S. K., Masumoto, Y., Taguchi, B., Komori, N., \& Yamagata, T. (2010). On the triggering of Benguela Niños: Remote equatorial versus local influences. Geophysical Research Letters, 37, L20604. https://doi.org/10.1029/2010GL044461

Richter, I., Behera, S. K., Masumoto, Y., Taguchi, B., Sasaki, H., \& Yamagata, T. (2013). Multiple causes of interannual sea surface temperature variability in the equatorial Atlantic Ocean. Nature Geoscience, 6(1), 43-47. https://doi.org/10.1038/ngeo1660

Ridgway, K. R., Dunn, J. R., \& Wilkin, J. L. (2002). Ocean interpolation by four-dimensional least squares-Application to the waters around Australia. Journal of Atmospheric and Oceanic Technology, 19(9), 1357-1375. https://doi.org/10.1175/1520-0426(2002)019<1357: OIBFDW > 2.0.CO;2 
Rodríguez-Fonseca, B., Mohino, E., Mechoso, C. R., Caminade, C., Biasutti, M., Gaetani, M., et al. (2015). Variability and predictability of West African droughts: A review on the role of sea surface temperature anomalies. Journal of Climate, 28(10), 4034-4060. https://doi. org/10.1175/JCLI-D-14-00130.1

Rouault, M. (2012). Bi-annual intrusion of tropical water in the northern Benguela upwelling. Geophysical Research Letters, 39 , L12606. https://doi.org/10.1029/2012GL052099

Rouault, M., Florenchie, P., Fauchereau, N., \& Reason, C. J. C. (2003). South East tropical Atlantic warm events and southern African rainfall. Geophysical Research Letters, 30, 8009. https://doi.org/10.1029/2002GL014840

Rouault, M., Illig, S., Bartholomae, C., Reason, C. J. C., \& Bentamy, A. (2007). Propagation and origin of warm anomalies in the Angola Benguela upwelling system in 2001. Journal of Marine Systems, 68(3-4), 473-488. https://doi.org/10.1016/j.jmarsys.2006.11.010

Rouault, M., Illig, S., Lübbecke, J., \& Imbol Koungue, R. A. (2018). Origin, development and demise of the 2010-2011 Benguela Niño. Journal of Marine Systems, 188, 39-48. https://doi.org/10.1016/j.jmarsys.2017.07.007

Rouault, M., Servain, J., Reason, C. J. C., Bourlès, B., Rouault, M. J., \& Fauchereau, N. (2009). Extension of PIRATA in the tropical South-East Atlantic: An initial one-year experiment. African Journal of Marine Science, 31(1), 63-71. https://doi.org/10.2989/ AJMS.2009.31.1.5.776

Ruiz-Barradas, A., Carton, J. A., \& Nigam, S. (2000). Structure of interannual-to-decadal climate variability in the tropical Atlantic sector. Journal of Climate, 13(18), 3285-3297. https://doi.org/10.1175/1520-0442(2000)013<3285:SOITDC >2.0.CO;2

Sciremammano, F. (1979). A suggestion for the presentation of correlations and their significance levels. Journal of Physical Oceanography, 9(6), 1273-1276. https://doi.org/10.1175/1520-0485(1979)009<1273:ASFTPO > 2.0.CO;2

Servain, J., Wainer, I., Ayina, H. L., \& Roquet, H. (2000). The relationship between the simulated climate variability modes of the tropical Atlantic. International Journal of Climatology, 20(9), 939-953. https://doi.org/10.1002/1097-0088(200007)20:9<939::AID-JOC511>3.0. $\mathrm{CO} ; 2-\mathrm{V}$

Shannon, L. V., Boyd, A. J., Brundrit, G. B., \& Taunton-Clark, J. (1986). On the existence of an El Niño-type phenomenon in the Benguela system. Journal of Marine Research, 44(3), 495-520. https://doi.org/10.1357/002224086788403105

Shchepetkin, A. F., \& McWilliams, J. C. (2005). The regional oceanic modeling system (ROMS): A split-explicit, free-surface, topographyfollowing-coordinate oceanic model. Ocean Model, 9(4), 347-404. https://doi.org/10.1016/j.ocemod.2004.08.002

Xie, S-.P., \& Carton, J. A. (2004). Tropical atlantic variability: Patterns, mechanisms, and impacts. In C. Wang, S.-P. Xie, \& J. A. Carton (Eds.), Earth's climate: The ocean-atmosphere interaction, Geophysical Monograph Series (121-142). Washington, DC: American Geophysical Union.

Zebiak, S. E. (1993). Air-sea interaction in the equatorial Atlantic region. Journal of Climate, 6(8), 1567-1586. https://doi.org/10.1175/15200442(1993)006<1567:AIITEA > 2.0.CO;2

Zelle, H., Appeldoorn, G., Burgers, G., \& van Oldenborgh, G. (2004). The relationship between sea surface temperature and thermocline depth in the eastern equatorial Pacific. Journal of Physical Oceanography, 34(3), 643-655. https://doi.org/10.1175/2523.1 